\title{
SENSING THE ELECTROKINETIC POTENTIAL OF CELLULOSIC FIBER SURFACES
}

\author{
Martin A. Hubbe
}

The charged nature of a cellulosic fiber surface is expected to play major roles in such phenomena as fiber dispersion, flocculation, adhesion, and adsorption of polyelectrolytes. This review focuses on the evaluation of such charges by means of electrokinetic measurements, with emphasis on the fiber-pad streaming potential technique. Results of recent experiments suggest that a continuous network or networks of pores below the outer surface of a kraft fiber can significantly contribute to observed streaming potential data. At present it is not clear whether the main subsurface contributions to the observed electrokinetic effects come from fibrillar layers on the fiber surfaces or from systems of nanopores within the cell walls of fibers. Based on the literature it is possible to suggest two conceptual models to account for the fact that the streaming potential of polymer-treated fibers can change in sign, dependent on the concentration of salt. Additional research is needed to clarify various theoretical and practical points. There may be opportunities to make more effective use of streaming potential tests in the future by carrying out such tests at reduced salt levels.

Keywords: Electrokinetics, Zeta potential, Streaming potential, Microelectrophoresis, Cellulose, Fibers, Papermaking, Cationic demand, Polyelectrolytes, Adsorption

Contact information: Department of Forest Biomaterials Science and Engineering, Campus Box 8005, Raleigh, NC27695-8005USA; hubbe@ncsu.edu

\section{THE CHARGED NATURE OF CELLULOSIC FIBERS}

\section{Why Study the Electrokinetics of Fibers?}

Electrical charges on surfaces can play a dominant role in the interactions of lignocellulosic materials (Davison and Cates 1975; Lindström 1996). This review focuses on sensing and quantifying effects of such charges by means of electrokinetic tests. The word "electrokinetics" implies that an electrical current or potential arises due to relative movement between two phases, as in the case of cellulosic fibers or fines suspended in water. From a practical standpoint, papermakers have used a variety of electrokinetic procedures to control and optimize the levels of additives (Hubbe 2000). Electrokinetic data can help to predict the dosages of highly charged materials that are needed to achieve different balances of stability vs. coagulation of suspensions (Verwey and Overbeek 1948; Hunter 1987; Lindström 1996), adsorption of strength-promoting additives (Strazdins 1980; Brouwer 1991; Spence et al. 1997; Thiele and Kopp 1997), retention of fine materials (Lindström et al. 1974; Tanaka 1984; Kumar 1991; Beck 1998), and maximum rates of water release during paper's formation (McKague et al. 1974; Davison and Cates 1975; Horn and Melzer 1975). In addition, the creping 
performance of tissue (Stitt 1998) and the performance of hydrophobic sizing agents (Poppel 1992) tend to be highly correlated with electrokinetic potential data.

In addition to the practical benefits, electrokinetic data have the potential to shed new light on the fundamental nature of cellulosic surfaces. After an overview of the most widely used electrokinetic test methods for samples of papermaking interest, this review will consider what the test data may be trying to tell us about the topography and nanoporosity of fibers.

Likely benefits of future work related to cellulose fiber charge may involve new composite technology, scaffolds for biological cell growth, membranes, and high-tech applications of paper. It makes sense that as our understanding of the ionic and morphological nature of fibers becomes clearer, we will be in a better position to pursue new technological approaches. At the same time it is important to bear in mind certain limitations of electrokinetic methods, making it necessary to combine a variety of analytical approaches to interpret what the data are trying to tell us about fiber surfaces.

\section{Factors Affecting Electrokinetic Potential of Cellulosic Fibers}

Chemical composition is perhaps the best place to begin in order to understand the charged nature of lignocellulosic surfaces exposed to aqueous solution. Previous studies, based on potentiometric, conductometric, and polyelectrolyte titrations, have done much to quantify the charge contributions of carboxylic acid groups and other functional groups that are accessible to different kinds of probe molecules (Lloyd and Horn 1993; Räsänen et al. 2001; Lindgren et al. 2002; Fardim and Holmbom 2005). For example, the kraft pulping and bleaching of wood fibers tends to decrease the relative amounts of extractives and lignin-related chemicals, thereby decreasing the negative character of the remaining solid material (Goulet and Stratton 1990; Lloyd and Horne 1993). Despite the fact that bleaching agents such as oxygen, ozone, and chlorine dioxide tend to convert various lignin moieties to carboxylic acids, much of this material tends to be solubilized and washed free of the pulp during subsequent alkaline extraction and washing operations (Goulet and Stratton 1990; Laine and Stenius 1997; Laine 1997).

Further changes in the observable charged nature of pulp fibers occur during mechanical processing. Papermakers often use the words "opening up" to describe what happens to fibers during refining, a process in which fiber suspensions are passed between grooved plates or conical surfaces, one of which is rotating. The repeated compression and shearing effects of the "bars" on the refiner plates cause cellulosic fibers to become internally delaminated, and the surfaces become fibrillated (Baker 1995). Though the area that is accessible to high-mass probes, such as cationic polyelectrolytes, tends to be increased by refining (Strazdins 1972), the zeta potential sometimes becomes less negative (Jacquelin and Bourlas 1964). The latter effect is due to the lesser proportions of lignin and extractives in the inner parts of the fiber cell wall (e.g. S2 sublayer), as compared to the outer ( $\mathrm{P}$ and $\mathrm{S} 1$ ) layers. At the same time, the increased effective surface area of the fibers means that a greater amount of cationic polymer needs to be added in order to achieve a neutral electrokinetic potential (Strazdins 1972; Davison and Cates 1975).

The drying of fibers can have effects that are almost the opposite of refining, in many respects. A high proportion of pores in the cell walls tend to close when kraft 
fibers are dried, and many of these pores remain closed if the fibers are subsequently rewetted (Stone and Scallan 1966). The once-dried fibers have a reduced ability to adsorb cationic polymers, compared to never-dried fibers of the same origin (Gruber et al. 1996).

The effects of solution $\mathrm{pH}$ on fiber charge and electrokinetic potential are complex. Not only does $\mathrm{pH}$ affect the dissociation of various different types of carboxylic acid (and other) groups within cellulosic fibers (Lloyd and Horne 1993; Herrington and Petzold 1992; Bygrave and Englezos 1998), but also there can be substantial changes in swelling, i.e., the relative amount of water held within the nanopores of the cell wall (Grignon and Scallan 1980; Scallan 1983; Lindström 1992). The latter effect would be expected to change the accessible surface area, depending on the size of the soluble ionic species used to evaluate the charged nature of the substrate.

Though it has been widely understood that increases in the concentrations of salts such as $\mathrm{NaCl}$ and $\mathrm{Na}_{2} \mathrm{SO}_{4}$ generally ought to decrease fiber swelling (Lindström 1992), as well as the overall importance of electrical charge interactions at fiber surfaces (Hunter 1987; van de Steeg et al. 1992), recent studies suggest that more attention needs to be paid to these issues. For instance, Fält and Wågberg (2003) observed that the amount of water held within fibers went through a maximum with respect to sodium sulfite concentration at approximately $0.05 \mathrm{M}$. This observation will be considered in more detail later in this article, since it provides some evidence regarding the nature of cellulosic surfaces. Various studies have shown that the amount of cationic polymer required to titrate cellulosic fiber suspensions to neutral charge tends to increase moderately with increasing salt. Test methods used in such analyses are discussed in the next section.

Some electrolytes have been found to affect the charged nature of cellulosic fibers to a much greater degree than others. Such differences have been attributed to the relative abilities of ions to form complexes with ionic groups at the cellulose surface (Grignon and Scallan 1980; Scallan 1983; Fält and Wågberg 2003) or to adsorb specifically within the condensed part of the layer of counter-ions (Hiemenz and Rajagopalan 1997). Such interactions have been found to follow a lyotropic series (Eagland and Allen 1977). Räsänen and Stenius (1997) concluded, however, that whereas protons interact specifically with fiber surfaces, the other ions are governed by a non-specific Donnan equilibrium.

Multivalent cations tend to have a much more dominant effect of fiber surface charges, compared to low-valence ions (Lindström and Söremark 1975). Polyelectrolytes often display high-affinity adsorption behavior on cellulosic fibers (Balodis 1967; Gruber et al. 1996), leading to dramatic changes in electrokinetic behavior.

\section{ELECTROKINETIC TESTS FOR PAPERMAKING APPLICATIONS}

Over the years a variety of electrokinetic methods have been developed, and many of them have been applied to the study of lignocellulosic materials. A common feature of such tests is some kind of movement of liquid relative to the solid surfaces (Sennett and Olivier 1965; Hunter 1981; Hidalgo-Alverez 1991; Müller 1996; Hiemenz 
and Rajagopalan 1997). The relative motion causes a flow of counter-ions adjacent to the surface, resulting in an electrical potential or a current. The structure of electrical double layers, i.e. the distribution of ions versus distance relative to charged surfaces, is described in well known textbooks (Verwey and Overbeek 1948; Hunter 1987; Hiemenz and Rajagopalan 1997).

In the following sections the most important techniques for measuring electrokinetic properties of fiber suspensions are presented, this includes microelectrophoresis, streaming current and streaming potential. The roles of external and internal surfaces are discussed in the context of recent streaming potential measurements.

\section{Micro-electrophoresis (ME)}

Of the various electrokinetic tests that have been applied to suspensions of cellulosic materials, microelectrophoresis (ME) probably has the best-established theoretical foundation (O'Brien and White 1978; Hunter 1981; Hidalgo-Alverez 1991; Farley 1992; Strazdins 1995). Briefly stated, one applies an electric field to a suspension of very small particles and evaluates the resulting velocity of particle motion. The experiment is typically carried out in a capillary tube or rectangular channel, using a strategy that helps to maintain laminar flow conditions.

Though many papermakers have used micro-electrophoresis methods, especially during the 1970s (Strazdins 1972; Melzer 1972; McKague et al. 1974; Davison and Cates 1975; Lindström and Söremark 1975), the method has developed a reputation as (a) being tedious, and (b) not always providing useful information. An inherent consequence of doing tests within a capillary cell is that an applied electric field will act upon counterions adjacent to the capillary walls, inducing electro-osmotic flow of the electrolyte solution. As long as the flow in the cell remains laminar, it is relatively straightforward to calculate the positions in the cell ("stationary levels") at which the net flow due to electro-osmosis equals zero. The adjective "tedious" probably arose due to the difficulty of viewing tiny points of lights (the particles) through a microscope. In addition, erroneous results can be expected if the operator fails to properly calibrate the focal plane. Settling of particulate debris within capillary cells (Tanaka 1984), affecting the calibration, has been a further source of frustration. Pelton et al. (1993) came up with a more robust procedure, measuring particle velocities at various points across the width of a capillary cell, and eliminating the need to separately determine the stationary levels.

Another possible criticism of the ME method, with respect to evaluation of cellulosic materials, is the fact that cellulosic fibers are much too large to fit into the types of capillary cells that are typically used. Rather, the common procedure involves filtering a suspension of papermaking stock with a coarse screen and placing the filtrate in the test device. Strazdins (1972) asserted that the zeta potential of fine materials tends to be representative of all of the surfaces within such a suspension. Data presented by Jaycock and Pearson (1976) is often cited in support of this statement; in the cited study the results of streaming potential tests of fibers agreed closely with micro-electrophoretic test results for fines. The cited study also demonstrated a mechanism whereby colloidal materials originating from the cellulosic pulp adsorbed onto various mineral surfaces, causing the respective zeta potentials to become closer to that of the cellulosic material. At the limits of short mixing times, and when using highly charged chemical additives, 
there are many examples in which surfaces of differing zeta potential have been found to coexist (Strazdins 1972; Sanders 1994; Wang and Hubbe 2001; Leiviskä et al. 2005). Possible sources of zeta potential difference among fine particles and fibers include differing content of extractives, hemicellulose, etc. (Rundlöf et al. 2000; Fardim and Holmbom 2005), differing affinities for potential adsorbates (Marton 1980), and different rates at which the suspended matter becomes saturated with a given adsorbate. While it is sometimes said that adsorption of materials onto fines is "more rapid," compared to adsorption onto larger fibers (Lindström and Söremark 1976), Strazdins (1994) is probably correct in stating that rates of arrival of adsorbate at various surfaces are almost independent of the size of a given particle or fiber. Rather, it appears that the fibers, being porous and covered by fibrils, can act like a sort of sponge, taking up greater quantities of adsorbate per unit of external area. This "sponge model" of the cellulosic surface will be considered in greater detail later in this review.

\section{Streaming Current (SC)}

Streaming current (SC) test methods have received considerably less theoretical analysis (Gerdes 1966; Cardwell 1966; Kenaga et al. 1967; Dentel and Kingery 1989; Ojala 1993; Walker et al. 1996; Phipps 1999), compared to the micro-electrophoresis methods discussed in the previous section. Nevertheless, the simple operation and robust nature of the equipment has led to the widespread use of SC methods both in the laboratory and online for the evaluation of aqueous samples from paper machines. The most commonly used SC devices employ a plastic piston, which reciprocates within a dead-ended plastic cylinder. The reciprocal motion, having a frequency of about $4 \mathrm{~Hz}$, causes a rapid movement of aqueous solution back and forth within the annular space. Electrode probes located at two points along the axis of the cylinder sense the electrical consequence of counter-ions, adjacent to the plastic walls, becoming moved back and forth by the liquid flow. A review of the SC method has appeared recently (Hubbe and Chen 2004).

The word "indirect" is perhaps the best adjective to describe how SC tests can be applied to the evaluation of lignocellulosic materials in suspension. SC methods have achieved great practical success as a means of detecting endpoints of polyelectrolyte titrations (Bley 1992; Kaunonen and Springer 1988; Hubbe and Chen 2004). In other words, one relies upon the assumption that whatever sign of polyelectrolyte is in excess in the aqueous phase of the sample will tend to dominate the charge at the plastic surfaces. The titration method is easily automated, and online SC titration systems have been installed on many paper machines (Kaunonen 1989; Bley and Kästner 1992; Bley and Bischof 1994; Baumgartner and Bley 1994; Gratton and Pruszynski 1995; Veal 1997; Denbrok and Peacock 1999; Berger et al. 2002). In many applications the test results are used to control the addition rate of a highly charged cationic polymer, keeping the cationic demand at a more constant level. The benefits of online charge control can include reduced overall costs of retention chemicals, more rapid dewatering, more efficient use of sizing agents, and reduced variability of paper properties.

Though it is hard to deny the practical utility and mechanical reliability of SC test methods, when used in paper mills, caution is required with respect to using SC procedures to gain information about what is happening at cellulosic surfaces. As noted 
by Jaycock (1995), it is difficult to be sure whether or not the plastic surfaces of the device have become completely covered by colloidal materials from the sample, as is required for the analysis to be valid. This issue is especially problematic in the case of samples that contain mainly hydrophilic polyelectrolytes. SC devices are often constructed of poly-tetrafluoroethylene (PTFE), a polymer that has a reputation for not sticking to anything. Certain combinations of low-charge, hydrophilic polyelectrolytes and moderate to high salt levels can cause highly misleading results of SC titrations or make it impossible to make the SC device reach a zero signal (Chen et al. 2001). Further deviations, relative to an assumed 1:1 stoichiometry of titration, have been attributed to the existence of charge-stabilized polyelectrolyte complexes (Chen et al. 2003).

Though the test surfaces of SC devices are plastic, rather than cellulosic, it is still possible to use SC titrations as a means of studying adsorption phenomena onto fibers (Cardwell 1966; Kenaga et al. 1967; Sezaki et al. 2006). Cardwell (1966) was the first to employ SC titrations in this manner, adding an excess of polyelectrolyte to a fiber slurry, then back-titrating aliquots of filtrate, to find the concentration of the initial polyelectrolyte remaining in the solution phase. Sezaki et al. (2006) extended this approach to cases involving polyampholytes, polymers containing both positive and negative dissociable groups. By adjusting the $\mathrm{pH}$ of the filtrate to either high or low $\mathrm{pH}$ it was possible to convert either the positive or negative groups to a neutral form and to titrate the polyampholyte as if it were a simple polyelectrolyte.

\section{Streaming Potential (SP)}

Quinke (1859) is credited with the earliest observation that an electrical potential results when liquid is passed though a porous plug or mat. Three wood fiber species were included among his samples. Helmholtz (1879) derived an expression showing that the voltage differences observed in such tests were more or less independent of the length, size, and form of the packed material through which the liquid was forced at a specific pressure, given a prescribed composition of electrolyte (Li and de Bruyn 1966). Thus,

$$
\zeta=4 \pi \eta \Omega E /(\varepsilon P)
$$

where $\zeta$ is the zeta potential (usually expressed in millivolts), $\eta$ is the viscosity of the solution, $\Omega$ is the electrical conductivity, $E$ is the measured change in electrical potential resulting from the application of pressure, $\varepsilon$ is the dielectric constant of the solution, and $P$ is the differential pressure applied across the sample. In his derivation, Helmholtz made two simplifying assumptions, as follows:

- The electrical double layers are thin relative to the dimensions of the passages through the porous material; and

- The solid materials and the surface of those materials are non-conductive under the conditions of testing.

As will become clearer in later parts of this review, neither of these assumptions is strictly true with respect to cellulosic fibers. A mat of wet cellulosic fibers has at least two classes of pore sizes - and probably three - as will be described in a later section. Since the pore sizes associated with a wet fiber mat can range from below $1 \mathrm{~nm}$ up to 
almost $1 \mathrm{~mm}$, the first assumption is likely to be violated, especially at the limit of low salt concentration. Wet, cellulosic fibers are known to be conductive (Briggs 1928; Scallan 1989; van de Ven 1999), in violation of Helmholtz's second assumption, though the effects of fiber conductance are often ignored when the bulk electrolyte concentration is higher than about $5 \mathrm{mM}$ (Goring and Mason 1950a; van Wagenen and Andrade 1980; Hunter 1987). The following form of the Helmholtz-Smoluchowski equation is often employed in order to account for fiber conductivity (Van Wagenen and Andrade 1976),

$$
\zeta=4 \pi \eta\left(\Omega_{\mathrm{B}}+2 \Omega_{\mathrm{S}} / a\right) E /(\varepsilon P),
$$

where $\Omega_{\mathrm{B}}$ is the bulk solution conductance, $\Omega_{\mathrm{S}}$ is the surface conductance, and $a$ is the radius of a pore, treated as being a cylinder. Equations (1) and (2) can be applied not only to packed beds of fibers, but also to capillary cells having various configurations (Anderson and Koh 1979; Schurz et al. 1989; Scales et al. 1992; Barron et al. 1994). In the case of a pad of fibers, it is often most practical to measure the electrical conductance through the pad, and then to use this value to determine a correction term equivalent to $2 \Omega_{\mathrm{S}} / a$ in Eq. (2).

As mentioned above, streaming potential tests have a very long history when applied to lignocellulosic materials (Quinke 1859). Briggs (1928) was apparently the first to apply the method in the case of pulp fibers intended to be used in paper production. Interestingly, Briggs was also the first to notice an issue that has concerned many subsequent investigators; that is, the ratio of potential drop to pressure drop across the fiber pad was not constant. Rather, the ratio depended on the applied pressure (see also Ball and Fuerstenau 1973). Briggs concluded, with considerable foresight, that the effect might involve the conductive nature of fiber surfaces. Remarkably, Briggs also observed that the streaming potential of fibers became increasingly negative with the addition of small amounts of $\mathrm{KCl}$, up to a concentration of $0.1 \mathrm{M}$. Both of these observations will be considered in more detail later in this review, since they provide clues to the nature of cellulosic fiber surfaces.

Despite the long and distinguished history of streaming potential analyses, papermakers have not adopted such tests to nearly as great an extent that they earlier adopted microelectrophoresis measurements, and more recently have come to rely on streaming current tests. At face value, this circumstance seems odd. After all, fiber-pad streaming potential tests are direct, sensing electrokinetic events occurring directly on the fiber surfaces under study (Hubbe and Wang 2004). No visual observations are required. It is not necessary to assume that the electrokinetic nature of the fiber surfaces is the same as that of the fines. Furthermore, it is not necessary to wait for the system to equilibrate with a second surface, such as plastic, in order to interpret the results. It will be argued, later in this review, that the relative unpopularity of the fiber-pad streaming potential method may stem from a well-founded, but misplaced reluctance on the part of papermakers to carry out any experiments with distilled water.

Online applications of streaming potential tests can involve even greater challenges. As noted by Winters (1998), online fiber-pad streaming potential tests can suffer from air bubbles, plugging of the screens, and build-up of material on the electrode probes. An extensive system of rinsing may be required in order to prevent fouling of the 
wetted parts of the device, especially if it is to be used continuously in a titration mode (Hubbe 1999).

It has long been recognized that subtle differences may exist between the environments of the two electrode probes that are used to evaluate the potential difference across a porous mat (Korpi and de Bruyn 1972; Ball and Fuerstenau 1973). To overcome this problem, some researchers have insisted upon using symmetrical devices in which the flow of liquid could be passed in either direction through a plug of porous material constrained between a pair of porous barriers (Fuerstenau 1956; Hoffman 1975; Jain et al. 1993). But such procedures require that a porous plug be individually prepared before each test. For practical use in evaluation of fibrous slurry samples, it is generally preferred to use flow of liquid to gather a plug or mat adjacent to a single screen, through which filtrate is pushed or drawn (Penniman 1991, 1992, 1994; Hand et al. 1993; Thiele and Kopp 1997; Wang and Hubbe 2001). Differences in the condition of the two electrode probes are dealt with, in such cases, by measuring a reference voltage in the absence of flow through the porous sample (Ball and Fuerstenau 1973; Penniman 1991; Wang and Hubbe 2001). The single-screen design for measuring streaming potential lends itself well to automated, online operation (Sack 1976; Evans et al. 1985; Ericksson 1987; Richter et al. 1989; Crill 1991; Sack et al. 1993; Rohloff and Höschle 1993; Nazir 1994; Penniman 1994; Miyanishi 1995a,b; Padovani and Colasurdo 1995; Petzold and Allen 1996; Hubbe 1999).

Despite the length of the above list of publications and patents pertaining to online use of streaming potential for paper machine slurry samples, the fact remains that usage of such devices is much less common in comparison to, for instance, streaming current (SC) methods, both online and in the lab. Paper machine systems employing online streaming potential measurements are the exception, rather than the rule (Crill 1991; Sack et al. 1993; Miyanishi and Shigeru 1997; Hubbe 1999; Miyanishi 1999). While practical issues, such as deposits and bubbles, may help explain why the method is not used more widely, the question arises as to whether or not papermakers have been satisfied that they have achieved meaningful correlations of the measurements with paper machine operating variables.

\section{Other Tests}

Although the test methods mentioned in the above three subsections are perhaps the best known, they don't exhaust the possible ways in which investigators have probed the electrokinetic nature of lignocellulosic surfaces. For example, one can characterize zeta potentials of suspended matter by either applying an alternating electrical field and sensing the intensity and phase of the resulting ultrasound (Springer and Taggart 1986) or, conversely, by applying an inaudible sound and detecting the resulting electrical fluctuations (Marlow et al. 1988). Both of these approaches work best when considering particles which have a compact shape and a large difference in density, relative to the suspending medium. Unfortunately, cellulosic fibers do not fulfill either of these requirements very well.

Two kinds of dye adsorption methods for fiber charge characterization deserve mention. Tanaka et al. (2000) developed an innovative method involving a strongly colored form of high-charge cationic polyelectrolyte. Measurements of the strength of 
coloration of filtrate solution, after mixing a known amount of polymer with a sample of interest, were used to calculate the adsorbed amounts, assuming an approximate 1:1 interaction of the polymer with accessible charged groups. Another straightforward strategy employs a basic dye such as methylene blue to quantify the accessible bound anionic groups in a mixture (Fardim and Holmbom 2003). Such dye molecules can be expected to interact with sites that are inaccessible to polyelectrolytes, depending on the molecular mass of the latter. Recently, a fluorescent dye has been used in order to quantify acidic groups at the surfaces of single fibers (Matthews et al. 2004).

A second dye-related method became quite popular, for a while, among papermakers seeking an alternative to microelectrophoresis tests (St. John and Gallagher 1992). Terayama (1952) observed that dyes such as toluidine blue-O changed their color when in the presence of an excess of strongly charged anionic polyelectrolyte, such as polyvinylsulfate. The primary use of the method, as originally conceived, has been to determine the endpoint of titrations involving polyelectrolytes. As in the case of SC tests, as described earlier, one can evaluate the amounts of polyelectrolyte adsorbing onto cellulosic fibers, based on evaluation of the concentration remaining in the bulk solution. The method was adapted and popularized, for paper industry applications, by Halabisky (1977). Halabisky modified the method such that titrations were carried out in both the positive and negative directions, each time adding a known excess of positive or negative polyelectrolyte to an aliquot of fiber suspension. Then, as a means of obtaining a single number to represent the system, a ratio was computed from the two endpoint quantities, and the log of the "colloid titration ratio" (CTR) was obtained. Values of the logarithm of CTR were often found to correlate well with zeta potential data (Springer and Taggart 1986; Carrasco et al. 1998). However, taking a ratio entails some loss of information pertaining to the ability of the sample to take up cationic and anionic polyelectrolytes. An alternative reporting system and procedure were proposed to avoid such loss of information (Hubbe 1979). More recently, the toluidine blue-O titration method has been incorporated into online determinations of cationic demand (Pursiheimo and Thomas 1998).

All of the charge evaluations mentioned so far have been based on an implicit assumption of an approximately 1:1 stoichiometry between polymer-bound ionic groups and surface-bound ionic groups. The assumption appears to be reasonably accurate at the limit of low ionic strength of the solution and in the absence of significant excess polyelectrolyte in the bulk solution (Wågberg et al. 1989; Laine et al. 1996; Koljonen et al. 2004; Horvath et al. 2006). Recently, Mocchiutti and Zanuttini (2005) published an elegant analysis of what can be expected when different levels of cationic polymer are added to a net-negative sample of papermaking fiber slurry. Though the initial polymer added to the system is expected to lie flat on the surface, higher amounts are expected to result in a three-dimensional adsorbed conformation, with loops and tails of polyelectrolyte extending outwards from the surface (see Fleer et al. 1993). The predicted deviations from 1:1 stoichiometric interaction between the polyelectrolyte and fiber surfaces were consistent with experimental data. 


\section{WHAT ELECTROKINETIC DATA CAN TELL US ABOUT FIBER SURFACES}

After having discussed various electrokinetic methods, the following question remains: "What can the test data tell us about fiber surfaces?" As pointed out near the beginning of this review, some of the equations most often used in interpreting electrokinetic test results appear to be based on unrealistic simplifying assumptions. Also, there seem to be some inconsistencies in the data, relative to what we think we know about cellulosic fiber surfaces. This section will take a different approach to these issues, making the tacit assumption that various sets of reported electrokinetic data are accurate. Instead, questions will be considered relative to what descriptions of fiber surfaces can best account for observed electrokinetic behavior.

As an example, consider the relative charge densities of cellulosic surfaces, in comparison with the charge densities of cationic polymers that are most commonly used in charge titration work. Chen et al. (2004) estimated that the charge density of such polymers is about one hundred times higher than the charge density of a cellulosic fiber surface, based on the proportion of bound carboxylic acid groups on the latter. Nevertheless, these authors detected a one-to-one stoichiometric interaction, based on an analysis of released counter-ions on the polyelectrolyte. It was concluded that the polyelectrolyte must be able to interact, somehow, with carboxylate groups within a three-dimensional volume, not just at the outer surfaces of the fibers.

Further evidence that cellulosic surfaces are somehow different from other materials that have been studied by electrokinetic methods date back to some of the earliest work in which the streaming potential method was applied to papermaking fiber suspensions (Briggs 1928; Bull 1934). Bull found that various different electrokinetic methods agreed well with one another when applied to protein-covered substrates. However, the methods failed to give consistent results when applied to cellulose. Briggs observed that the magnitude of negative zeta potential of cellulose fibers, as calculated from streaming potential measurements, increased with increasing salt concentration, reaching a maximum at $0.1 \mathrm{M} \mathrm{KCl}$.

\section{Towards More Realistic Descriptions of Cellulosic Surfaces}

Earlier in this article brief mention was made of a "sponge" model for the cellulose fiber. In other words, it was proposed that cationic polyelectrolytes diffusing towards a cellulosic fiber surface may gradually continue diffusing into sub-surface regions of the fiber. Such regions may involve, for instance, fibrillation at the fiber surfaces or pores within the cell walls. Such diffusion may account for at least part of the observed decay of zeta potentials of cellulosic surfaces freshly treated with cationic polyelectrolytes (Strazdins 1977; Penniman 1992; Koethe and Scott 1993; Farley 1997; Wang and Hubbe 2002; Hubbe et al. 2006a). Hostetler and Swanson (1974) confirmed the general concept of the mechanism by studying the adsorption of cationic polymers of differing molecular mass onto silica gel suspensions of differing known pore size. Figure 1 provides a cartoon representation of such a mechanism.

As shown, if the amount of adsorbed polyelectrolyte is sufficient to reverse the inherent negative zeta potential of the cellulosic fiber surfaces, then one expects there to be an excess of negatively charged counter-ions, such as chloride or sulfate, adjacent to 
the treated fiber surfaces. Flow past the freshly-treated surfaces is expected to push some of these counter-ions, those which are located in the diffuse parts of electrical doublelayers outside of a plane of shear (Hunter 1987). The expected result is a positive streaming potential. A decay of streaming potential is expected if the polyelectrolytes are able to adsorb into dead-ended pores (see Part B of figure), causing the external surfaces to revert to a net-negative condition.
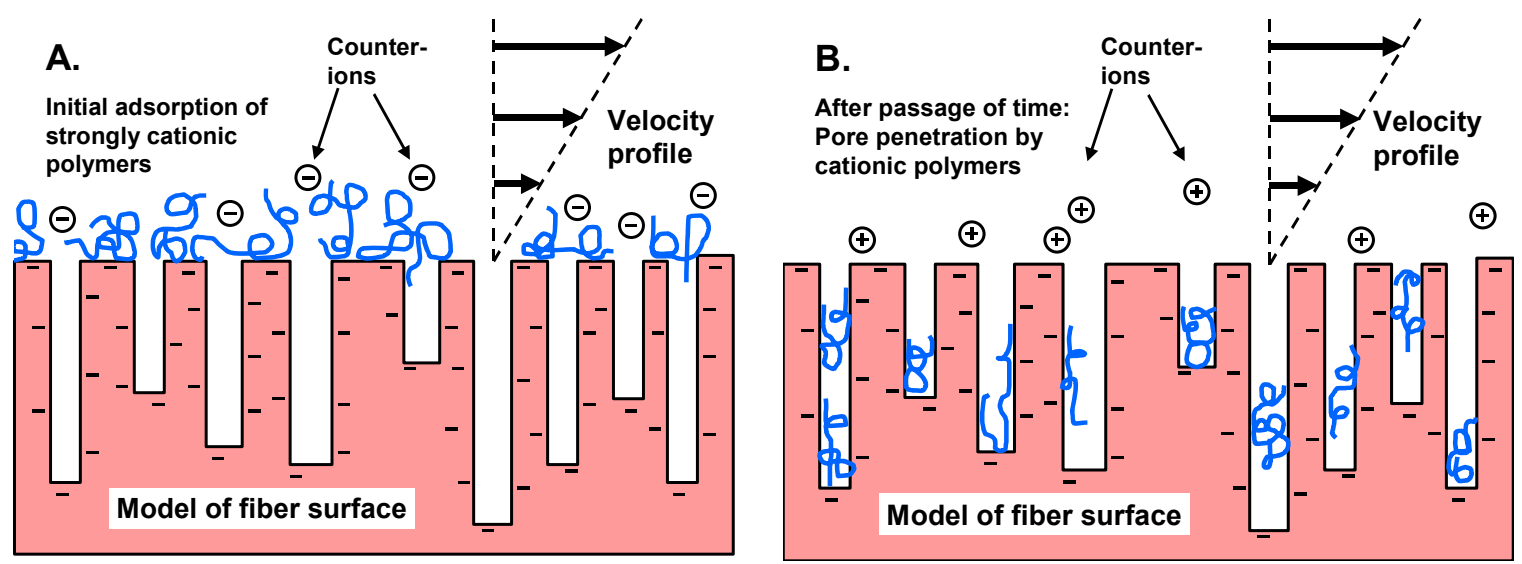

Fig. 1. Model of cellulose fiber surface in which pores are considered as being discontinuous, open at one end, and sufficiently large to permit diffusion of polyelectrolytes. Flow past the outer surface pushes counter-ions, resulting in an electrokinetic current and potential. Part A: Initial situation following adsorption of high-charge cationic polymer. Part B: After diffusion of polymer into pores.

Various authors have considered the effects of loops and tails of macromolecules extending outwards from substrates (Jones 1979; Vernhet et al. 1994; Ohshima 1997; Bauer et al 1998). The consensus of such work is that extended macromolecules are expected to shift the location of a shear plane further outwards from a surface. Such effects are expected to be important in the case of cellulose fibers, due to the presence of fibrils and microfibrils (Pelton 1993; Rojas et al. 1998, 2000; Rojas and Neuman 1999).

Estimates of the pore sizes within the cell walls of chemically pulped fibers from wood were first obtained by a solute exclusion method (Stone and Scallan 1968). Briefly stated, a known mass of never-dried fibers was suspended in a known total amount of water with a known amount of dissolved dextrin, having a narrow distribution of molecular mass. Depending on the molecular mass of the polymer, the authors observed that the concentration in the bulk solution was higher than would have been expected, had the polymer been able to penetrate into all of the pores that were accessible to water. Though the results of solute exclusion tests have indicated pore widths of at least 5-20 $\mathrm{nm}$ in the case of sulfite and kraft pulps (Stone and Scallan 1968; Berthold and Salmén), it has been pointed out that the initial analysis did not account for excluded volume effects, which can result from a restriction in the degrees of freedom of motion of dissolved polymer segments when confined to a very small pore (Alince and van de Ven 1997). Alince (2002) concluded, based on adsorption experiments with cationic polyelectrolytes, that typical pores in kraft fibers have widths of about $100 \mathrm{~nm}$. The latter figure also tended to agree with electron micrographs given in the same article. 
Further evidence to support a pore-diffusion model, including the model depicted in Fig. 1, can be found in the results of various adsorption tests of cationic materials onto cellulosic fibers. For instance, Öhman et al. (1997) observed relatively high apparent charge of the fiber surfaces when the analysis was based on $\mathrm{pH}$ titrations, i.e. the adsorption of $\mathrm{H}_{3} \mathrm{O}^{+}$ions. By contrast, analyses based on adsorption of cationic polymers yielded lower apparent charge, especially in the case of the highest-mass polymer used as probes. Such results are consistent with the existence of a class of pores that are accessible to simple ions, but are too small to allow ready diffusion of the polyelectrolytes. Unfortunately, this type of test result can be questioned due to the strong reversal of electrokinetic charge often observed after solid substrates are exposed to an excess of high-mass polyelectrolyte (Hoogeveen et al. 1996; Sukhorukov et al. 1998; Schwarz et al. 1998; Wågberg and Ödberg 2000). The reversal appears to result due to the existence of loops and tails extending towards the solution phase, where they are expected to have a dominating effect on the electrostatic interactions of those surfaces (Varoqui 1982; Ohshima 1997).

Though both zeta potential decay and the results of solute exclusion tests can be explained in terms of the diagram in Fig. 1, the photographic evidence just cited (Alince 2002) suggests that it would be more accurate to think in terms of continuous networks of pores below the outer surfaces of cellulosic fibers. Figure 2 shows two kinds of pores that ought to be considered in order to account for the electrokinetic behavior of cellulosic fibers. Part A of the figure assumes that the main observable effects arise due to flow within layers of fibrils and microfibrils at fiber surfaces. Such layers may or may not be accessible to polyelectrolytes, depending on such factors as molecular mass, time, degree of refining of the fibers, and depth of location at the fiber surface. Part B of the figure assumes that the main observable effects arise due to flows within the fiber cell walls, and that the electrokinetic contribution of such flow is greater than that of flow within fibrillar layers at fiber surfaces. It is assumed in both parts A and B that the pore networks are continuous, at least during the time that the fibers remain wetted and swollen with water.

A.

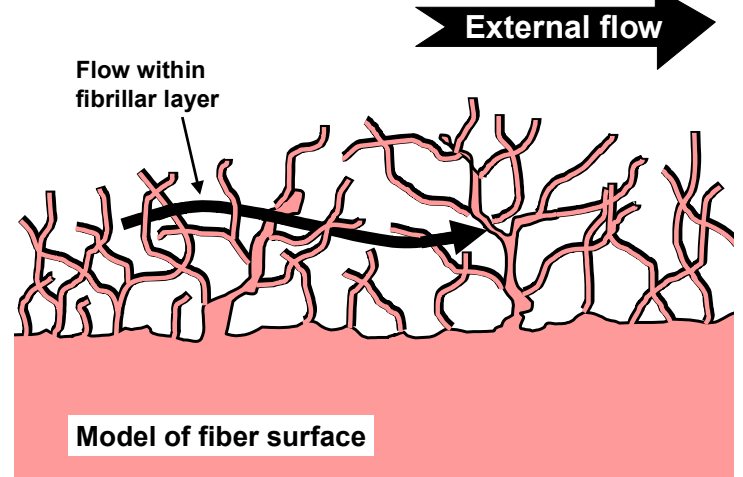

B.

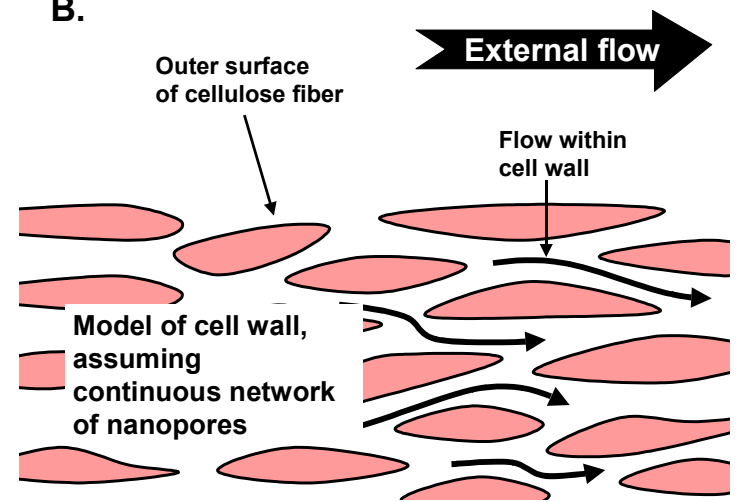

Fig. 2. Two types of continuous pores networks associated with cellulosic fibers. Part A: Pore network within a layer of fibrils and microfibrils at a fiber surface. Part B: Pore network within the cell wall of a fiber, especially after chemical pulping to remove lignin. 
The degree of fibrillation of fiber surfaces is expected to depend on the degree to which the fibers have been refined (Baker 1995). As noted by Pelton (1993), fibrils can range all the way down to molecular dimensions, making it difficult even to define the location of a true outer surface of cellulosic fibers. Given the wide range of sizes of different fibrillar elements at the surfaces of refined fibers, it makes sense to expect void spaces as large as about $100 \mu \mathrm{m}$ within a layer of such fibrils. This estimate is about a factor of 1000 larger than what has been estimated for the size of pores in the cell walls of chemically pulped fibers. The lower limit of pore size within a layer of fibrils might depend on such factors as packing pressure of a fiber mat, as well as electrical doublelayer forces of repulsion between adjacent fibrils. Pang and Gray (1998) demonstrated that the degree of extension of fibrils outward from fiber surfaces tended to decrease with the addition of salt, consistent with the reduced influence of electrostatic repulsion between the surfaces. Forsström et al. (2005) concluded that water within fibrillar layers on kraft fibers can account for a substantial fraction of the water remaining with the fibers following centrifugation, according to the water retention value (WRV) procedure.

\section{Evidence Based on Fiber Electrical Conductance}

When considering which of the figures presented so far best accounts for physical reality, one of the first types of evidence to consider is the conductivity of wet fibers. According to Scallan (1989), wetted fibers are about 20 times more conductive of electricity in comparison to a $10^{-4}$ molar salt solution. As mentioned earlier, various authors have used corrections for "surface conductance" of fibers, especially in cases where the concentration of salt in the bulk solution was below about 1 to $5 \times 10^{-4} \mathrm{M}$ (Goring and Mason 1950a; Ghosh and Pal 1961; van Wagenen and Andrade 1980; Hunter 1987; Revil et al. 1999; van de Ven 1999). The conductivity of wet fibers is said to be too high to be due only to the counter-ions at the outer surface of the fibers (van de Ven 1999). Rather, it would appear that a flow of current passes through the cell wall (as in Fig. 2B) or within layers of fibrils at the fiber surfaces (as in Fig. 2A). In this regard, the term "surface conductance" maybe ought to be replaced by a more general term such as "conductance of wet fibers." Goring and Mason (1950b) discussed a model roughly equivalent to Fig. 2A, hypothesizing that cellulosic chains, bearing negatively charged groups, were "partially dissolved" at the fiber surfaces.

\section{Evidence based on Effects of Fiber Pad Compression}

Earlier, when introducing Helmholtz's (1879) analysis of streaming potential, it was mentioned that Helmholtz made two simplifying assumptions. Not only did he assume that the packed materials (including their surfaces) were non-conductive, but he also assumed that the double layers were thin relative to the dimensions of the pore spaces. Evidence pertaining to the latter assumption comes from many experiments in which streaming potential was evaluated over a range of different pad densities of cellulosic fibers. Pad density was found to have a significant effect on calculated zeta potentials (Neale 1946; Goring and Mason 1950b; Chang and Robertson 1967a; Melzer 1972), though none of the cited studies offered a mechanistic explanation. Interestingly, Briggs (1928) already had observed an effect of applied pressure on zeta potentials 
calculated from streaming potential data; higher applied pressures of water would be expected to have effects similar to that of mechanical compression of a fiber mat.

A possible explanation for the observed effects of packing density is proposed as follows: With increasing compression of a fiber pad, the various pores within the pad are shifted towards smaller sizes. Assuming that the condition of the aqueous solution remains constant, the ratio of the pore size to the thickness of the ionic double layer is shifted. In the case of very small pores, such as those within the cell wall (rather than between adjacent fibers), a decrease in pore diameter would be expected to increase the degree of overlap of ionic double layers on adjacent pore surfaces. A suppression of electrokinetic phenomena is expected in such cases (Hunter 1981; Miller et al. 1992; Wan 1997; Bernabé 1998; Ricq et al. 1998; Revil et al. 1999; Alkafeef et al. 2001). One way to explain the suppression effect is that a double-layer, of the type expected at an outside surface, "cannot fit" within the available space. Equivalently, it is expected that the local $\mathrm{pH}$ within very narrow pores, at low ionic strength, can be shifted relative to its bulk value (Grignon and Scallan 1980; Fält and Wågberg 2003). A greater proportion of carboxylate groups within the pore would be in their protonated, uncharged state. The following expression provides an estimate of the ratio between streaming current within a nanopore, versus that of an equivalent unbounded surface (Alkafeef et al. 2001),

$$
r=1-\tanh (\kappa h) /(\kappa h)
$$

where $r$ is the ratio of streaming current in a narrow pore of width $h$ in comparison to the streaming current in a pore many times larger than the Debye length $\kappa^{-1}$ corresponding to the ionic strength of the flowing aqueous solution. Figure 3 illustrates the dependency of $r$ on the product $k h$, according to Eq. 3 .

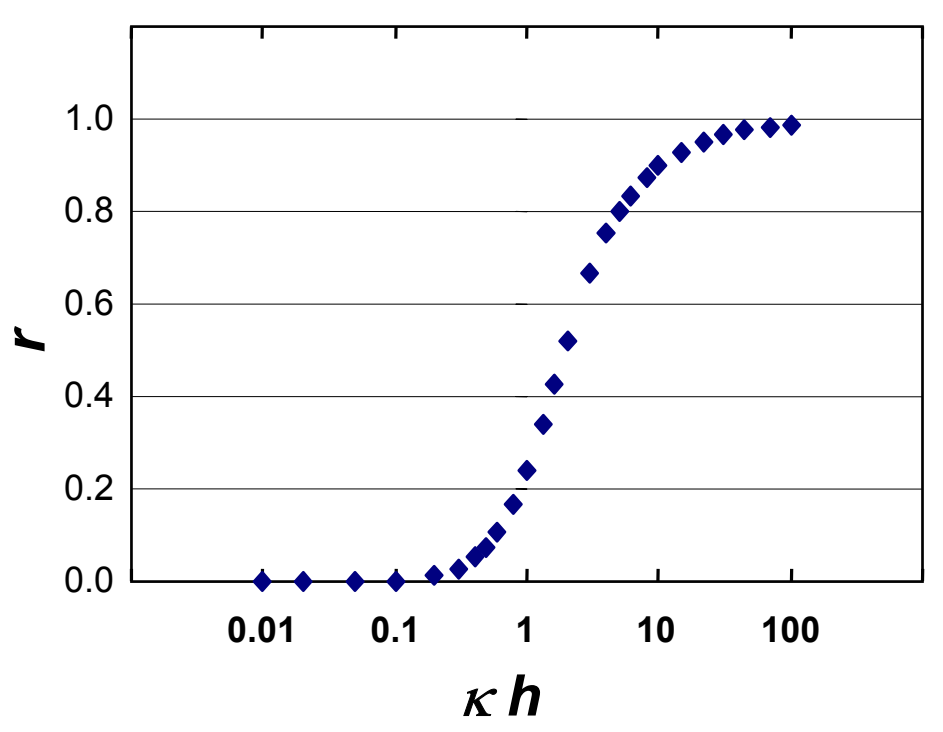

Fig. 3. Factor $r$ describing relative magnitude of streaming current within a small capillary having a thickness of $\kappa h$, where $\kappa$ is the Debye-Hückel reciprocal length parameter describing the double layer thickness. 
Let's suppose that the explanation just given is valid, accounting for the observed dependency of streaming potential on pad compression. It does not necessarily follow, however, that pores within the cell wall of a fiber provide a continuous passage for the flow of liquid, in response to an applied external pressure. It is alternatively possible that a class of extremely small pores exists within the compressed layers of fibrils and microfibrils at the fiber surfaces. These two alternatives are basically the same as was represented earlier in Fig. 2. Tentatively, it is proposed that nano-sized pores exist both within the cell wall itself and within fibrillar layers. At the same time, there may be larger pores between adjacent fibers within a mat.

Another competing or parallel explanation for the effect of pad compression on zeta potential values calculated from streaming potential data involves the conductivity of the fibers or of the fiber surfaces (Ghosh and Pal 1961; van Wagenen and Andrade 1980; van de Ven 1999; Revil et al. 1999). There are two ways in which compression of a fiber pad can be expected to change the relative contribution of fiber conductance to the net, observed streaming potential. First, by forcing the pore openings to become smaller, on average, there is a lower conductance of electricity via the liquid phase. Second, it might be expected that pressing conductive fibers together would facilitate the flow of current from one fiber surface to the next. In support of such a mechanism, Scallan (1989) showed increasing conductance with increasing solids contents of fiber pads, especially in the case of fibers that were rich in ionic groups.

\section{Evidence Based on Reversible Sign of Streaming Potential}

A recent study provided further evidence that a continuous network of pores exists below the outer surface of cellulosic fibers (Hubbe et al. 2006a). The experimental situation is shown schematically in Fig. 4.
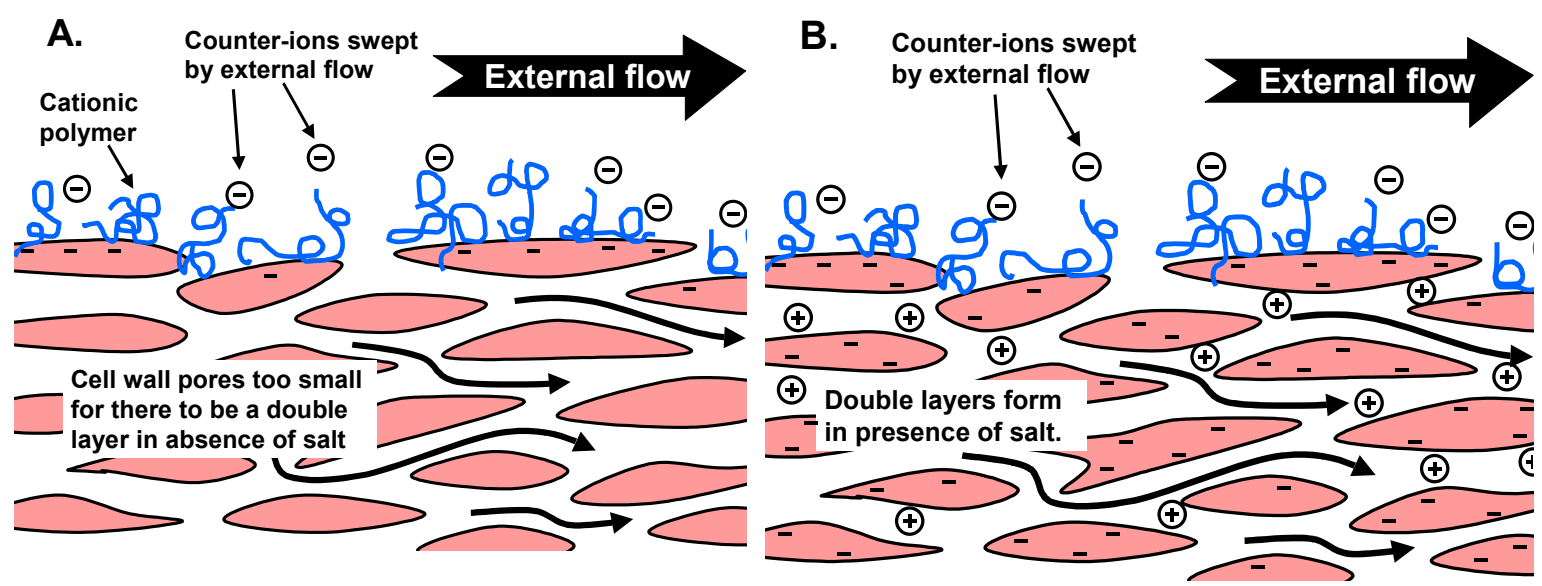

Fig. 4. Model of fiber surface showing contrasting contributions to the sign of streaming potential. Part A: In the absence of salt, most of the electrokinetic signal is expected to come from external surfaces, which are accessible to adsorption by high-mass cationic polyelectrolyte; the surfaces within nanopores don't contribute significantly, since there is not enough space to accommodate a double layer and the $\mathrm{pH}$ is shifted. Part $\mathrm{B}$ : In the presence of salt the double layers within nanopores develop more fully, but the electrokinetic contribution is negative, based on the assumption that the polyelectrolytes cannot reach those surfaces. 
Before forming the fiber pad, a slurry of bleached hardwood kraft fibers in $10^{-4} \mathrm{M}$ $\mathrm{NaHCO}_{3}$ was treated with high-mass poly-diallyldimethylammonium chloride (polyDADMAC). The amount of poly-DADMAC was selected so that it was about twice the amount needed in order to achieve a neutral streaming potential. A strongly positive streaming potential was observed. Upon addition of sodium sulfate to the mixture, the sign of the observed streaming potential became negative. Then, by a series of dewatering, dilution, and salt addition steps, the fibers were alternated between salt-free and salt-containing conditions. The sign of streaming potential accordingly switched back and forth, in a quasi-reversible manner.

Referring again to Fig. 4, the reversible switching of sign of streaming potential is consistent with the expectation that the electrokinetic contribution of nano-sized pores will be suppressed in the absence of salt (Alkafeef et al. 2001). Then, upon addition of salt (part B of figure), the double-layers become compressed. When the double layers are thin, relative to the size of a certain class of pores, then Helmholtz's (1879) assumptions are more closely fulfilled. Thus, the electrokinetic phenomena within the smallest pores begin to approach what would be expected in the case of large pores or adjacent to external surfaces exposed to solution. The situation depicted in Fig. 4 happens to be a very effective way of demonstrating this kind of behavior, since the polyelectrolytes are expected to be too large to diffuse easily below the outer surfaces of the fibers.

Based on the accumulated evidence, it is now possible to form a conceptual picture of cellulosic fibers, relative to their interactions with charged polymers. In summary, it appears that fibers have continuous networks of pores below their outer surfaces. At least some of these pores appear to be smaller than about $50 \mathrm{~nm}$, small enough that their effect on the observed electrokinetics of the system become suppressed when the electrical conductivity is reduced to about $60 \mu \mathrm{S} / \mathrm{cm}$. The data also imply that the very fine pores can be too small to be efficiently covered by the high-mass polyDADMAC molecules, and that they can remain negative in character, even while the outer surface of the fibers can become positive, following the adsorption of high-charge cationic polymer. The basic mechanisms were confirmed recently by similar experiments with suspensions of silica gel (Hubbe et al. 2006b), a material having more narrowly defined pore dimensions.

\section{Pictorial Models}

Figure 5 shows two ways in which the concepts just described can be reconciled with features of cellulosic fibers already discussed in this article. Part A considers a case in which it is assumed that relatively large pores exist between fibers in a compressed mat. It is assumed that any pores in the fibers, existing below the level accessible to polyelectrolytes, must be similar in size or smaller than the thickness of the double layer, as expressed by the Debye $\kappa^{-1}$ parameter, especially in the absence of added salt. It is reasonable to expect that such nanopores will be present not only within the cell walls, but also among microfibrils at fiber surfaces, especially if the latter have become mechanically squeezed together. Though there is evidence that high-mass cationic polymers initial adsorb only on the outermost surfaces of kraft fibers (Tatsumi and Yamauchi 1997; Hubbe et al. 2006a), there is also evidence suggesting that gradual 
diffusion into the fiber takes place (Strazdins 1977; Penniman 1992; Koethe and Scott 1993; Farley 1997; Wang and Hubbe 2002; Hubbe et al. 2006a). Given the tiny dimensions of pores in the cell wall, relative to the size of typical polyelectrolytes used in papermaking, it is reasonable to expect that such diffusion is mainly limited to penetration below layers of fibrils.
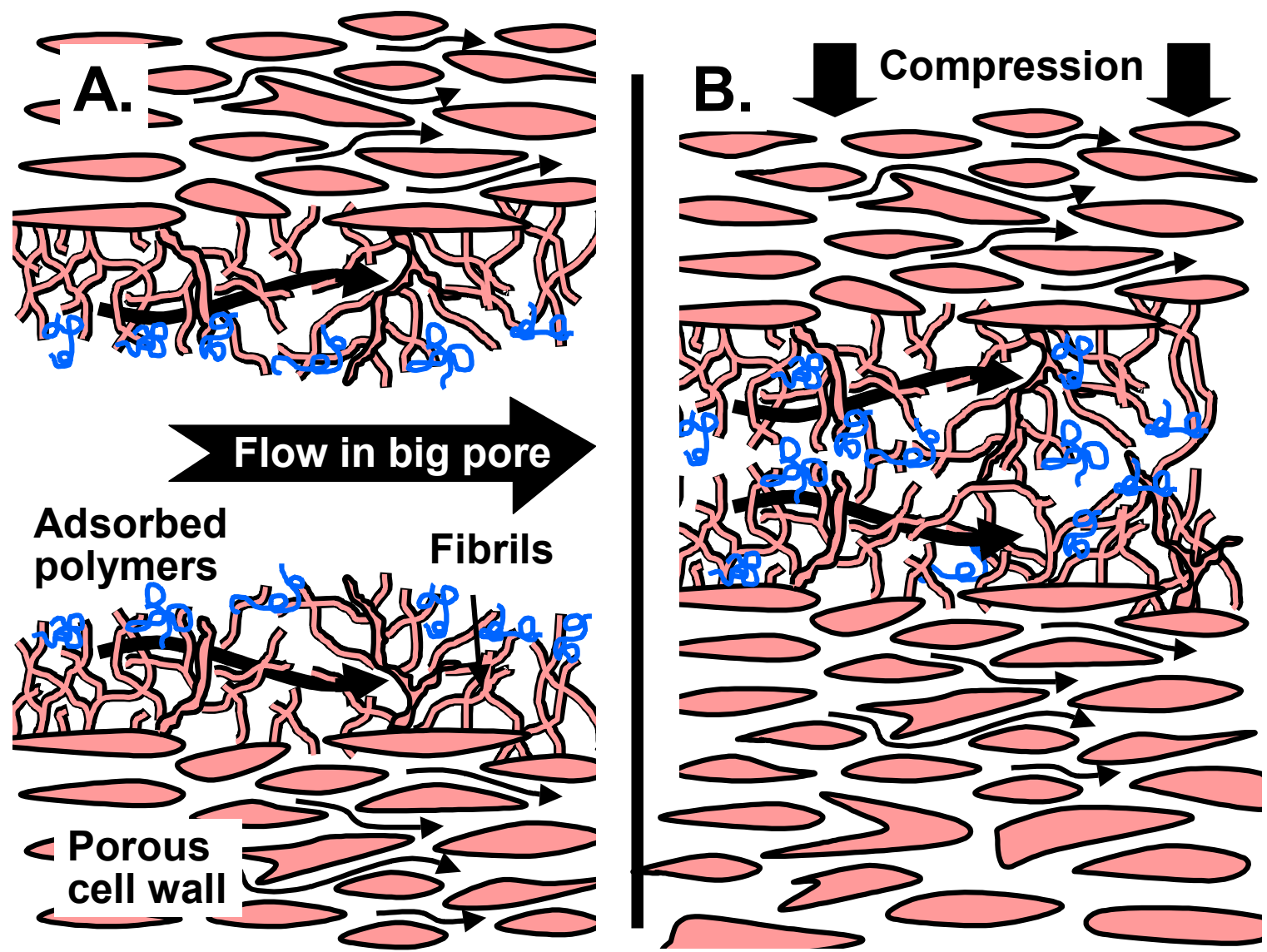

Fig. 5. Two alternative interpretations to account for reversal of sign of streaming potential upon addition or removal of salt from cellulosic fiber suspension treated with high-mass cationic polyelectrolyte. Part A: Model in which positive streaming potential, in the absence of salt, is assumed to arise mainly due to flow in macro-pores past the outer surfaces of the fibers, to which the polyelectrolyte is adsorbed. Electrokinetic effects due to nanopores within the fibrillar layer and cell walls are assumed to be significantly suppressed in the absence of salt. Part B: Model in which it is assumed that large pores are not the main contribution to streaming potential, due to compression of the mat. Polyelectrolytes are assumed to diffuse within the fibrillar layers at the fiber surface, but not significantly into the cell wall pores. In either case, addition of salt is expected to increase the relative importance of the electrokinetic effects arising within the smaller pores.

Part B of Fig. 5 shows an alternative interpretation to describe what has been learned from the recent experimental work. In this model it is assumed that the fibers in the mat, during an analysis of streaming potential, have been sufficiently compressed so that fibrillar layers on adjacent fibers are pushed against one another. Because streaming potential is directly proportional to applied pressure of a fluid, it follows that a majority of the electrokinetic signal will arise as the fluid passes through points of greatest 
resistance within the mat, i.e., fibrillar layers and fiber cell walls, rather than the open volumes between such features. In contrast to the model shown in Part A, one has to assume that the pores within the fibrillar layers are mainly accessible to polyelectrolyte adsorption, and that their typical size is substantially larger than that within the cell walls. These assumptions are needed in order to account for the observed changes in the sign of streaming potential, upon addition or removal of salt (Hubbe et al. 2006a). Because Fig. 4 presents two possible models, rather than one, it is clear that there is a need for further research to be able to answer such questions as whether fibrillar layers or nanopores within cell walls tend to have a larger effect on observed electrokinetic effects.

\section{Reappraisal of some Early Data}

Much time has passed since the earliest detailed measurements of the streaming potential of pulp fibers (Briggs 1928). Certain aspects of that study have long remained unexplained. As noted earlier in this review, Briggs observed that zeta potential values calculated from the observed streaming potentials first increased in absolute value as the salt concentration was increased from zero. Such a trend is contrary to what would be expected based on a simple double-layer concept, involving a planar surface (Hiemenz and Rajagopalan 1997). Two hypotheses to explain those results can be attempted now, in light of the concepts presented in Fig. 5.

First, let us assume that the observed effect was due to the "suppression" of electrokinetic effects represented by Eq. (3). Thus, in the absence of salt, only the flow around the fibers, by way of relatively large passages, is expected to contribute significantly to the streaming potential. If that were the only component of flow, then, neglecting the conductivity correction, one might use Eq. (1) as an approximation to calculate the streaming potential. However, because the suppression term in Eq. (3) needs to be applied to the electrokinetic effect within the tiny pores within the cell wall, one expects that the overall effect will be lower in absolute magnitude. Though the direction of the trend is consistent with the observations (Briggs 1928), it is not possible, in the absence of detailed knowledge of pore structures, to give a quantitative estimate. A detailed analysis would need to include the conductivity correction.

The explanation just given also can help account for the observation of Fält and Wågberg (2003), who observed a maximum in the degree of fiber swelling at a certain concentration of salt. Likewise, Li and Dai (2004) observed increasing water retention of bleached eucalyptus pulp upon addition of 0.03 to $0.1 \%$ of either $\mathrm{NaCl}$ or $\mathrm{CaCl}_{2}$ in different cases. In the absence of salt, the double layers within the smallest pores are expected to be strongly suppressed, as already noted, so the expected osmotic pressure should be correspondingly weak. With increased salt, the double layers will have sufficient room to become well established, leading to a maximization of the effect. Further salt is expected to make the double layers thin relative to the pore dimensions, leading to a reduction of swelling effects, as shown in many studies (Grignon and Scallan 1980; Lindström and Carlsson 1982; Scallan 1983; Fält and Wågberg 2003).

A second explanation for Briggs' observation can be based on expected effects of fiber electrical conductance. In the absence of salt, the effect of such conductance can be attributed to the presence of counter-ions adjacent to acidic groups within the pore structures of fibers. If one assumes that these groups remain dissociated, regardless of 
the changes in salt concentration, then it follows that fiber conductivity will contribute less and less to the net streaming potential as the salt concentration is raised. Applying Eq. (3), it follows that the calculated zeta potential may increase with increasing salt. Further increase in salt is expected to reduce the thickness of the double layer sufficiently that a lower proportion of the counter-ions are located outside of the hydrodynamic slip plane, so that the calculated zeta potential is expected to decrease as high levels of salt are approached. Though these effects are, once again, in the correct direction to account for Briggs' (1928) observations, a detailed analysis would need to relax the assumption of a constant degree of dissociation (Lindgren et al. 2002).

The foregoing discussion has attempted to deal separately with each of Helmholtz's main assumptions, i.e., non-conducting solids and thin double layers related to pores sizes. When considering the conductance of cellulosic fiber cell walls, however, one can combine the two concepts as follows: At low ionic strength the double layers cannot be accommodated within the space of nanopores in the cell walls, and the local $\mathrm{pH}$ becomes depressed on the nanopore surfaces, relative to the bulk $\mathrm{pH}$. It follows that the counter-ions can be greatly reduced, in comparison to what might be expected based on the surface concentration of dissociable groups. With increasing ionic strength of the bulk solution, the double layers become more fully developed, the $\mathrm{pH}$ within nanopores becomes closer to the bulk $\mathrm{pH}$, and the carboxyl groups within the nanopores become more substantially dissociated. This description is consistent with the observed increasing specific conductance of cellulosic fibers with increasing salt concentration, within a low concentration range (Scallan 1989). Likewise, when Chowdiah et al. (1983) considered the interpretation of streaming potential data within narrow pores wetted by non-aqueous media, they concluded that a correction for conductivity (e.g. Eq. 3), was accurate only for pores that are large relative to $\kappa^{-1}$. For narrower pores, the analysis also needed to account for the overlap of double-layers from the adjacent solid surfaces.

\section{Practical Limitations}

Any detailed discussion of papermaking's electrokinetic aspects runs the risk of neglecting other important factors. Such factors, which often play a dominant role in various papermaking operations, include polymeric bridging attachments, hydrodynamic shear forces, and mechanical sieving of fine materials. Though many practical studies have shown strong correlations between electrokinetic measurements and the optimization of paper machine operations (Chang and Robertson 1967b; Strazdins 1977, 1980; Stratton and Swanson 1981; Kumar et al. 1991; Poppel 1992; Vanderhoek 1994; Miyanishi and Montegi 1996), such correlations can be hard to discern when looking at routine data from paper mills. For instance, it has been found that zeta potential has little correlation with fines retention in cases where the fiber slurry is formed into paper in the presence of high levels of hydrodynamic shear (Horn and Linhart 1991; Stratton and Swanson 1981; Stark and Eichinger 1989; Tripattharanan et al. 2004). In such cases, it is necessary to use very high-mass retention aids which possess the capability of physically bridging between surfaces in order to achieve high levels of retention.

Caution also is needed when considering electrokinetic events within a papermaking fiber suspension are dominated by materials in the colloidal phase (Smith 1992). In other words, the net charges associated with the fiber surfaces may be 
insignificant relative to the surface charge contribution of materials that cannot be filtered. In such cases, it makes sense to focus on the cationic demand of the mixture, not on the streaming potential of the fibers. A previous review deals with the selection of the most appropriate electrokinetic test to use, depending on the type of sample, and also depending on the kind of question that one wants to answer (Hubbe 2000).

\section{PATHS FORWARD}

\section{Cellulose Characterization}

When one considers the results of various studies cited in this review, it is clear that both theoretical and practical questions remain. On the theoretical side, although there is evidence that pores of different sizes are influencing electrokinetic signals in distinct ways, the electrokinetic data alone cannot tell us the location of these pores. In this regard, it would make sense to run experiments in which nanofibrillar material has been optionally removed from fiber surfaces by means of enzymes (Jackson et al. 1993; Özdil et al. 2003; Buschle-Diller et al. 2005). Then, matched sets of enzyme-treated and untreated fiber suspensions could be treated with sufficient cationic polymer to strongly reverse the streaming potential to positive in the absence of salt. If the tests were to show a reversible sign of potential for both types of fiber, then the results would be consistent with a significant contribution to electrokinetic signals coming from continuous network of pores within the cell wall of fibers. If, however, the test results were to show substantially less reversibility in the case of the enzymatically treated fibers, then the results would indicate a substantial contribution of the fibrillar layers to the observed electrokinetic effects.

As illustrated by some of the studies cited in this article, complementary test protocols can be a great help to understand phenomena that are only partially revealed by electrokinetic measurements. As in the work of Tatsumi and Yamauchi (1997), depth analysis methods might be used to test some theories regarding the extent to which polyelectrolytes of different molecular mass can penetrate either into a fibrillar layer or into the cell wall of fibers prepared by different pulping methods. Adsorption isotherms would be a second way to probe differences in accessible surface area before and after such processes as refining, enzymatic treatments, and drying of the fibers.

Another approach to this kind of research might involve mathematical models of porosity within packed beds of fibers, and determining whether reasonable models of porosity are consistent with expected effects of streaming potential and electro-osmotic effects within a network of pores. In particular, it would be interesting to carry out fluid dynamic calculations, finding out the extent to which electro-osmotic effects, induced by streaming potential, might cause local flows within nanopores to be in the opposite direction from applied external pressure. The results of a related study suggest that such work could yield interesting findings (Erickson and Li 2001).

Another type of needed research concerns the conductivity of fibers. Though the word "surface" has been used to describe the type of fiber conductivity that affects streaming potential results (Ghosh and Pal 1961), the work cited in the present review points in the direction of a three-dimensional effect. On the one hand, one may picture a 
set of bound carboxylic acid groups existing within a "gel" of hemicellulose or oxidized cellulose chains that fill the volume beneath an outermost surface of the fibers (Goring and Mason 1950b; Pelton 1993). Alternatively, one may picture those same kinds of charges existing on exposed surfaces within nanopores or larger pores (Stone and Scallan 1968; Alince and van de Ven 1997). Since it has been found that some of the intermediate to larger pores within cell walls tend to close preferentially when chemically pulped cellulosic fibers are dried (Stone and Scallan 1966), it would make sense to measure the effects of drying on subsequent fiber conductivity, when the fibers are rewetted. Similar experiments could be carried out on fibers that have been "polished" by mild enzymatic treatment (Jackson et al. 1993; Özdil et al. 2003; Buschle-Diller et al. 2005).

\section{Fiber Modification}

Electrokinetic measurements also have potential for monitoring and control of certain chemical modifications of fibers. In particular, it is well known that cellulosic fibers can be treated to increase their negative charge (Waleka 1956; Lindström and Carlsson, 1982; Roberts and Tatham, 1992; Laine 1997; Hubbe et al. 1999). In principle, such strategies have the potential to make the fibers more receptive to cationic starch (Marton and Marton 1976), ketene dimer size formulations (Isogai et al. 1997), and other cationic additives. Curing reactions of polyamidoamine-epichlorohydrin type wetstrength agents, in particular, are expected to be enhanced if the fibers are first treated to increase their carboxyl group content (Wågberg and Björklund 1993; Espy 1994, 1995; Saito and Isogai 2005). In addition, it has been shown that an enhanced negative charge of fiber surfaces can promote inter-fiber bonding (Walecka 1956; Didwania 1969; Roberts and Tatham, 1992), even without the addition of cationic polyelectrolytes.

It would make sense to carry out streaming potential titrations in the absence of salt in order to evaluate the net charge of the outermost surfaces of fibers, which had been treated in different ways to vary their negative character. By selection of treatment conditions it is possible to direct fiber modification reactions either to the bulk of the fiber cell wall or just to the outer exposed surface. For example, by suspending fibers in a non-swelling solvent, chemical derivatization reactions of cellulose mainly are excluded from the bulk of the fiber (Ehrnrooth et al. 1977). By contrast, similar reactions in the presence of a swelling solvent resulted in a pervasive reaction, throughout the cell wall thickness. In the case of aqueous phase fiber treatments, the location of chemical reaction depends on the fiber's history of pulping and drying (Barzyk et al. 1997). Because a large proportion of the pores in the kraft pulp fiber tend to close irreversibly during drying (Stone and Scallan 1966), the penetration of various reagents tends to be limited. Thus, when recycled kraft fibers are chemically treated in the aqueous phase, the effects are expected to be more surface-specific, compared to never-dried fibers. A number of studies have shown advantages, such as combinations of increased bonding strength and relatively low apparent density resulting from such treatments (Barzyk et al. 1997). Streaming potential tests at contrasting salt levels, as described earlier in this article could be a powerful way to determine whether the effects of fiber modification mainly affect just the outsides of the fibers, or whether the effects of treatment have permeated the nanoporous structure of the cell wall. 


\section{Online Control}

Automation has become almost an expectation when electrokinetic tests are to be applied to modern industrial processes. In the case of papermaking, it would seem that significant information can be obtained by at least three classes of electrokinetic tests, as follows:

Ionic demand: Streaming current titrations, and their automated applications, were already described earlier in this review (see also Hubbe and Chen 2004). Such tests appear to give reliable information about the cationic demand of various aqueous samples that contain dissolved polyelectrolytes and colloidal substances. Despite the fact that some of the online streaming current titrating systems can employ automatic filtration of fiber slurries, there does not appear to be any publication describing online titration of whole furnish suspensions. To carry out such an analysis, all that is needed is to pretreat the fiber suspension with an excess of polyelectrolyte, filter the suspension, and then back-titrate an aliquot of the filtrate with polyelectrolyte solution of the opposite charge.

Zeta potential of fines: Micro-electrophoresis tests of fiber fines and other particulate materials tend to work well in a laboratory setting, but there may be a considerable challenge to apply such tests online in paper mills. Automation itself is not the main problem, since laser-Doppler technology can be used to obtain distributions of particle velocities almost instantaneously (Sanders 1994; Leiviskää et al. 2005). The contamination of capillary cells is a much more serious issue, especially when one considers the high levels of dissolved and colloidal materials present in typical paper machine process waters. However, because the zeta potential of fine materials taken from a paper machine system can change rapidly upon storage (Strazdins 1995), there is a great need for online testing. A resurgence in zeta potential analysis of fines would appear to be very likely, dependent on development of truly robust micro-electrophoresis equipment, not dependent on the use of capillary cells.

Streaming potential of fibers: As has already been described, it would appear that fiber-pad streaming potential tests can offer considerable advantages in terms of online monitoring and control of outcomes related to the fiber surfaces. The measurements are direct, meaning that the electrokinetic events one is detecting take place immediately on the fiber surfaces that comprise the greatest part of the mass of dry paper.

Modern automation methods make it increasingly reasonable to consider a wide range of analytical procedures, not limited to conventional titrations or straightforward measurements of streaming potential. For instance, one could envision a device that automatically carries out streaming potential titrations at two or more defined levels of solution conductivity. Laboratory results from this kind of testing suggest that the lowconductivity tests would provide a much more accurate means of optimizing paper machine systems to maximize drainage rates and improve the efficiency of retention (Hubbe et al. 2006a). In adopting such a practice, papermakers would be asked to violate a long-standing taboo against carrying out tests in deionized water. For instance, it does not make sense to evaluate retention aids or other wet-end additives in the absence of salt, since such experimental results are less likely to predict the performance of those additives on the paper machine, where salts are present. But in cases where one is 
primarily interested optimizing the performance of a paper machine, there is an incentive to try something unconventional. The required procedure requires initial filtration of fiber slurry samples, followed by dilution with salt-free solution, followed by evaluation of streaming potential. By this means the influence of subsurface nanopores can be selectively excluded, making it possible to sense charge effects due to the outermost surfaces of fibers.

\section{REFERENCES CITED}

Alince, B. (2002). "Porosity of swollen pulp fibers revisited," Nordic Pulp Paper Res. J. $17(1), 71-73$.

Alince, B., and van de Ven, T. G. M. (1997). "Porosity of swollen pulp fibers evaluated by polymer adsorption," in C. F. Baker, ed., The Fundamentals of Papermaking Materials, Pira Intl., Leatherhead, Surrey, UK, 771-788.

Alkafeef, S., Gochin, R. J., and Smith A. L. (2001). "The effect of double layer overlap on measured streaming currents for toluene flowing through sandstone cores," Colloids Surf. A 195(1-3), 77-80.

Anderson, J. L., and Koh, W. (1979). "Electrokinetic parameters for capillaries of different geometries," J. Colloid Interface Sci. 59(1), 149-158.

Baker, C. F. (1995). "Good practice for refining the types of fiber found in modern paper furnishes," Tappi J. 78(2), 147-153.

Ball, B., and Fuerstenau, D. W. (1973). "A review of the measurement of streaming potentials," Miner. Sci. Eng. 5(4), 267-277.

Balodis, V. (1967). "Electrokinetic properties of fiber surfaces," Appita 21(3), 96-103.

Barron, W., Murray, B. S., Scales, P. J., Healy, T. W., Dixon, D. R., and Pascoe, M. (1994). "The streaming current detector: A comparison with conventional electrokinetic techniques," Colloids Surf. A. 88(2-3), 129-139.

Barzyk, D., Page, D. H., and Ragauskas, A. (1997). "Acidic group topochemistry and fiber-to-fiber specific bond strength,” J. Pulp Paper Sci. 23(2), J59-J61.

Bauer, D., Killmann, E., and Jaeger, W. (1998). "Flocculation and stabilization of colloidal silica by the adsorption of poly-diallyl-dimethyl-ammonium chlroide (PDADMAC) and of copolymers of DADMAC with $N$-methyl- $N$-vinyl-acetamide (NMVA)," Colloid Polym. Sci. 276(8), 698-708.

Baumgartner, H., and Bley, L. (1994). "Practical experiences with online charge titration on a paper machine," Wochbl. Papierfabr. 122(22), 894-898.

Beck, M. W. (1998). "Wet-end chemistry and paper machine stability," Paper Technol. 39(3), 33-38.

Berger, R., Renaud, S., and Waters, K. (2002). "Applying automatic chemical control from stock prep to the machine," Appita J. 55(3), 197-201.

Bernabé, Y. (1998). "Streaming potential in heterogeneous networks," J. Geophys Res. 103(B9), 20,827-20,841.

Berthold, J., and Salmén, L. (1997). "Effects of mechanical and chemical treatments on the pore-size distribution in wood pulps examined by inverse size-exclusion chromatography (ISEC)," J. Pulp Paper Sci. 23(6), J245-253. 
Bley, L. (1992). "Measuring the concentration of anionic trash - the PCD," Paper Technol. 33(4), 32-37.

Bley, L., and Bischof, P. (1994). "Practical experiences with on-line charge titration in paper mills," Wochenbl. Papierfabr. 122(22), 894-898.

Bley, L., and Kästner, M. (1992). "On-line process charge control in papermaking," in The Chemistry of Papermaking, Proc. PIRA Conf., Jan. 28-29, 1992, paper 17.

Bley, L., and Winter, E. (1997). "On-line charge monitoring - a wet-end strategy," Proc. 1997 Engineering \& Papermakers Conf., 297-301.

Briggs, D. R. (1928). "The determination of the zeta potential on cellulose - A Method," J. Phys. Chem. 33(5), 641-675.

Brouwer, P. H. (1991). "The relationship between zeta potential and ionic demand and how it affects wet-end retention," Tappi J. 74(1), 170-179.

Bull, H. B. (1934). "Electrokinetics. 14. A critical comparison of electrophoresis, streaming potential, and electrosmosis," J. Phys. Chem. 30(5), 577-583.

Buschle-Diller, G., Inglesby, M. K., and Wu, Y. (2005). "Physicochemical properties of chemically and enzymatically modified cellulosic surfaces," Colloids Surf. A. 260(13), 63-70.

Bygrave, G. and Englezos, P. (1998). "Fiber charge from potentiometric titration of kraft pulp and Donnan equilibrium theory," Nordic Pulp Paper Res. J. 13(3), 220224.

Cardwell, P. H. (1966). "Adsorption studies using a streaming current detector," J. Colloid Interface Sci. 22(5), 430-437.

Carrasco, T., Mutjé, P., and Pelach, M. A. (1998). "Control of retention in paper-making by colloid titration and zeta potential techniques," Wood Sci. Technol. 32(2), 145-155.

Chang, M. Y. and Robertson, A. A. (1967a). "Zeta potential measurements of fibers. DC. streaming current method," Can. J. Chem. Eng. 45(2), 66-71.

Chang, M. Y., and Robertson, A. A. (1967b). "Flocculation studies of fiber suspensions: Influence of zeta potential," Pulp Paper Mag. Can. 68(9), T438-T444.

Chen, J., Hubbe, M. A., and Heitmann, J. A. (2001). "Measurement of colloidal charge in the paper mill by streaming current," TAPPI 2001 Papermakers Conf., electronic document, TAPPI Press, Atlanta.

Chen, J., Heitmann, J. A., and Hubbe, M. A. (2003). "Dependency of polyelectrolyte complex stoichiometry on the order of addition. 1. Effect of salt concentration during streaming current titrations with strong poly-acid and poly-base," Colloids Surf. A 223(1-3), 215-230.

Chen, S.-L., Wang, S., and Lucia, L. A. (2004). "New insights into the fundamental nature of lignocellulosic fiber surface charge," J. Colloid Interface Sci. 275(2), 392397.

Chowdiah, P., Wasan, D. T., and Gidaspow, D. (1983). "On the interpretation of streaming potential data in nonaqueous media," Colloids Surf. A 7(4), 291-299.

Crill, M. (1991). "Fiber charge analyzers monitor furnish to optimize production," Pulp Paper 65(11), 92-95.

Davison, R. W., and Cates, R. E. (1975). "Electrokinetic effects in papermaking systems: Theory and practice," Paper Technol. Ind. 16(4), 107-144. 
Denbrok, C., and Peacock, B. (1999). "Wet-end charge measurement using streaming current online titrators," Tappi J. 82(10), 57-59.

Dentel S. K., and Kingery, K. M. (1989). "Theoretical principles of streaming current detection," Water Sci. Tech. 21, 443-453.

Didwania, H. P. (1969). "The mechanism of strength increases in paper on hydroxyehtylation of fibers," Tappi 52(8), 1511-1517.

Eagland, D., and Allen, A. P. (1977). "The influence of hydration upon the potential at the shear plane (zeta potential) of a hydrophobic surface in the presence of various electrolytes," J. Colloid Interface Sci 58(2), 230-241.

Ehrnrooth, E., Htun, M., and de Ruvo, A. (1977). "Esterification as a means of improving the properties of once-dried fibers," in Fiber-Water Interactions in Papermaking, Trans. Symp. Oxford, 899-911.

Eriksson, R. (1987). "Method and apparatus for measuring the streaming potential of a particle suspension," U.S. Pat. 4,687,986.

Erickson, D., and Li, D. Q. (2001). "Streaming potential and streaming current methods for characterizing heterogeneous solid surfaces," J. Colloid Interface Sci. 237(2), 283-289.

Espy, H. H. (1994). "Alkaline-curing polymeric amine-epichlorohydrin resins," in WetStrength Resins and their Application, L. L. Chan, ed., TAPPI Press, Atlanta, Ch. 2, 13-44.

Espy, H. H. (1995). "The mechanism of wet-strength development in paper. A review," Tappi J. 78(4), 90-99.

Evans, B. E., Hemm, S. R., and Russell, R. A. V. (1985). "Apparatus for determining an electrical characteristic of a fibrous dispersion," U.S. Pat 4,535,285.

Fält, S., and Wågberg, L. (2003). "Influence of electrolytes on the swelling and strength of kraft-liner pulps," Nordic Pulp Paper Res. J. 18(1), 69-73.

Fardim, P., and Holmbom, B. (2003). "Fast determination of anionic groups in different pulp fibers by methylene blue sorption," Tappi J. 2(10), 28-32.

Fardim, P., and Holmbom, B. (2005). "Origin and surface distribution of anionic groups in different papermaking fibers," Colloids Surf. A 252, 237-242.

Farley, C. E. (1992). "Microelectrophoresis as a wet end chemistry teaching tool," Proc. TAPPI 1992 Papermakers Conf., TAPPI Press, Atlanta, 509-512.

Farley, C. E. (1997). "Factors influencing the rate of charge decay," Tappi J. 80 (10), 177-183.

Fleer, G. J., Cohen Stuart, M. A., Scheutjens, J. M. H. M., Cosgrove, T., and Vincent, B., eds. (1993). Polymers at Interfaces, Chapman and Hall, London, ISBN 0412581604, 343-375.

Forsström, J., Andreasson, B., and Wågberg, L. (2005). "Influence of pore structure and water retaining ability of fibers on the strength of papers from unbleached kraft fibers," Nordic Pulp Paper Res. J. 20(2), 176-185.

Fuerstenau, D. W. (1956). "Measuring zeta potentials by streaming potential techniques," Trans. AIME 205, 834-835.

Gerdes, W. F. (1966). "A new instrument - The streaming current detector," $12^{\text {th }}$ Natl. ISA Analysis Inst. Symp., Houston, TX, 181-198. 
Ghosh, B. N., and Pal, P.K. (1961). "Evaluation of zeta potential with correction of cell constant and surface conductance," Trans. Faraday Soc. 57, 116-122.

Goring, D. A. I., and Mason, S. G. (1950a). "Electrokinetic properties of cellulose fibers. 1. Stream potential and electro-osmosis," Can. J. Res. B 28(6), 307-322.

Goring, D. A. I., and Mason, S. G. (1950b). "Electrokinetic properties of cellulose fibers. 2. Zeta-potential measurements by the stream-compression method," Can. J. Res. B 28(6), 323-338.

Goulet, M. T., and Stratton, R. A. (1990). "The effect of pulping, bleaching, and refining operations on the electrokinetic properties of wood fines," Nordic Pulp Paper Res. J. 5(3), 118-125.

Gratton, R., and Pruszynski, P. (1995). "Cationic demand survey of paper machines: how can we measure and use it," Pulp Paper Can. 93(3), T103-T108.

Grignon, J., and Scallan, A. M. (1980). "Effect of $\mathrm{pH}$ and neutral salts upon the swelling of cellulose gels." J. Appl Polymer Sci. 25(12), 2829-2843.

Gruber, E., Grossmann, K., and Schempp, W. (1996). "Interactions of synthetic cationic polymers with fibers and fillers; influence on adsorption," Wochenbl. Papierfabr. 124(1), 4-11.

Halabisky, D. D. (1977). "Wet end control for effective use of cationic starch," Tappi 60(12), 125-127.

Hand, V., Koethe, J., Kuchibhotla, S., and Scott, W. (1993). "An evaluation of two padforming paper stock charge analyzers," Papermakers Conf. Proc., TAPPI Press, Atlanta, 591-598.

Helmholtz, H. (1879). "Study Concerning Electrical Boundary Layers," Weidemann Annalen der Physik $u$. Chemie, $3^{\text {rd }}$ Ser., 7, 337-382.

Herrington, T. M., and Petzold, J. C. (1992). "An investigation into the nature of charge on the surface of papermaking woodpulps. 1. Charge/pH isotherms," Colloids Surf. 64(2), 97-108.

Hidalgo-Alverez, R. (1991). "On the conversion of experimental electrokinetic data into double-layer characteristics in solid-liquid interfaces," Adv. Colloid Interface Sci. 34, 217-341.

Hiemenz, P.C., and Rajagopalan, R. (1997). Principles of Colloid and Surface Science, $3^{\text {rd }}$ Ed., Dekker, New York.

Hoffman, F., Müller, F., Rohloff, E., and Tretter, H. (1975). "Experiences with the streaming potential method for retention and wet strength problems," Papier 29(12), 529-534.

Hoogeveen, N. G., Cohen Stuart, M. A., Fleer, G. J., and Böhmer, M. R. (1996). "Formation and stability of multilayers of polyelectrolytes," Langmuir 12(15), 36753681.

Horn, D., and Linhart, F. (1991). "Retention Aids," in Paper Chemistry, J. Roberts (ed.), Blackie, Glasgow, Chapter 4, 44-62.

Horn, D., and Melzer, J. (1975). "The effect of high molecular cationic dewatering aids on the electrokinetic properties of pulp," Papier 29(12), 534-541.

Horvath, A. E., Lindström, T., and Laine, J. (2006). "On the indirect polyelectrolyte titration of cellulosic fibers. Conditions for charge stoichiometry and comparison with ESCA," Langmuir 22(2), 824-830. 
Hostetler, R. E., and Swanson, J. W. (1974). "Diffusion into and adsorption of polyethylenimine on porous silica gel," J. Poly. Sci. 12(1), 29-43.

Hubbe, M. A. (1979). "A modified reporting procedure for polyelectrolyte titrations," Tappi 62(8), 120-121.

Hubbe, M. A. (1999). "Method and apparatus for measuring an electrical property of papermaking furnish," U.S. Patent 5,936,151.

Hubbe, M. A. (2000). "Selecting and interpreting colloidal charge measurements," in Proc. Scientific \& Technical Advances in Wet End Chemistry, Barcelona, Spain, PIRA Intl., Leatherhead, UK.

Hubbe, M. A., and Chen, J. (2004). "Charge-related measurements - A reappraisal. Part 1. Streaming current," Paper Technol. 45(8), 17-23.

Hubbe, M. A., Rojas, O. J., Lee, S. Y., Park, S., and Wang, Y. (2006b). "Distinctive electrokinetic behavior of nanoporous silica particles treated with cationic polyelectrolyte," Colloids Surf. A., accepted.

Hubbe, M. A., Rojas, O. J., Lucian, L. A., and Jung, T. M. (2006a). "Consequences of the nanoporosity of cellulosic fibers on their streaming potential and their interactions with cationic polyelectrolytes," Cellulose, submitted.

Hubbe, M. A., Wagle, D. G., and Ruckel, E. R. (1999). "Method for increasing the strength of a paper or paperboard product," U. S. Pat. 5,958,180.

Hubbe, M. A. and Wang, F. (2004). "Charge-related measurements - A reappraisal. Part 2: Fiber-pad streaming potential," Paper Technol. 45(9), 27-34.

Hunter, R. J. (1981). Zeta Potential in Colloid Science, Academic Press, London.

Hunter, R. J. (1987). Foundations of Colloid Science, Clarendon Press, Oxford, UK.

Isogai, A., Kitaoka, C., and Onabe, F. (1997). "Effects of carboxyl groups in pulp on retention of alkylketene dimer," J. Pulp Paper Res. J. 23(5), J215-J219.

Jackson, L. S., Heitmann, J. A., and Joyce, T. W. (1993). "Enzymatic modifications of secondary fiber," Tappi J. 76(3), 147-154.

Jacquelin, G., and Bourlas, H. (1964). "Measurement of the zeta potential of papermaking fibers. Effects of preliminary treatments," Techniques et Recherches Papeteries 3, 49-58.

Jain, L., Bharati, S., and Bharati, R. (1993). "Electrochemical potential in papermaking: significance and an instrument for measurement," IPPTA 5(3), 39-47.

Jaycock, M. J. (1995). "Assumptions made in the measurement of zeta-potential by streaming current/potential detectors," Paper Technol. 36(3), 35-38.

Jaycock, M. J., and Pearson, J. L. (1976). "Study of the retention of pigment during paper formation," J. Colloid Interface Sci. 55(1), 181-190.

Jones, I. S. (1979). "A theory of electrophoresis of large colloid particles with adsorbed polyelectrolyte," J. Colloid Interface Sci. 68(3), 451-461.

Kaunonen, A. (1989). "Online retention and cationic demand measurements and their utilization on a paper machine," Paperi Puu 71(1), 46-52.

Kaunonen, A., and Springer, A. M. (1988). "Evaluation of piston type streaming current detector for pulp and paper applications," TAPPI Papermakers Conf. Proc., TAPPI Press, Atlanta, 225-230. 
Kenaga, D. L., Kindler, W. A., and Meyer, F. J. (1967). "Studies of adsorption of cationic polyelectrolytes on pulp using streaming current detection," Tappi 50(7), 381-387.

Koethe, J. L., and Scott, W. E. (1993). "Polyelectrolyte interactions with papermaking fibers: The mechanism of surface-charge decay," Tappi J. 76(12), 123-133.

Koljonen, K., Mustaranta, A., and Stenius, P. (2004). "Surface characterization of mechanical pulps by polyelectrolyte adsorption," Nordic Pulp Paper Res. J. 19(4), 495-505.

Korpi, G. K., and De Bruyn, P. L. (1972). "Measurement of streaming potentials," J. Colloid Interface Sci. 40(2), 263-266.

Kumar, V., Jain, L., Bharati, R., Bharati, S., and Agrawal, S. K. (1991). "Application of zeta potential for retention optimization of bagasse pulp," IPPTA 3(3), 46-49.

Laine, J. (1997). "Effect of ECF and TCF bleaching on the charge properties of kraft pulp," Paperi Puu 79(8), 551-559.

Laine, J., Buchert, J., Viikari, L., and Stenius, P. (1996). "Characterization of unbleached kraft pulps by enzymatic treatment, potentiometric titration and polyelectrolyte adsorption," Holzforschung 50(3), 208-214.

Laine, J., and Stenius, P. (1997). "Effect of charge on the fiber and paper properties of bleached industrial kraft pulps," Paperi Puu 79(4), 257-266.

Leiviskä, T., Rämö, J., Sillanpää, M., and Vuorenpalo, V.-M. (2005). "Multimodal zeta potential distributions in chemical pulp bleaching filtrates," J. Pulp Paper Sci. 31(4), 167-174.

Li, H. C., and De Bruyn, P. L. (1966). "Electrokinetic and adsorption studies on quartz," Surf. Sci. 5(2), 203-220.

Li, S., and Dai, H. (2004). "The influences of inorganic salts on WRV of papermaking stock," Proc. $2^{\text {nd }}$ Intl. Symp. Techol. Pulping Papermaking Biotech. Fiber Plants $\left(2^{\text {nd }}\right.$ ISTPPBFP), Nanjing Forestry Univ., Oct. 13-14, 434-437.

Lindgren, H., Öhman, L.-O., Gunnars, S., and Wågberg, L. (2002.) “Charge determinations of cellulose fibers of different origin - Comparison between different methods," Nordic Pulp Paper Res. J. 17(1), 89-96.

Lindström, T. (1992). "Chemical factors affecting the behavior of fibers during papermaking." Nordic Pulp Paper Res. J. 7(4), 181-192.

Lindström, T. (1996). "Electrokinetics of the papermaking industry," in J. C. Roberts, ed., Paper Chemistry, $2^{\text {nd }}$ Ed., Blackie Academic, New York, Ch. 3, 25-43.

Lindström, T., and Carlsson, G. (1982). "The effect of carboxyl groups and their ionic form during drying on the hornification of cellulose fibers," Svensk Papperstidn. 85(11), R146-R151.

Lindström, T., and Söremark, C. (1975). “Zeta potential measurement during paper manufacture," Papier 29(12), 519-525.

Lindström, T., and Söremark, C. (1976). "Adsorption of cationic polyacrylamides on cellulose," J. Colloid Interface Sci. 55(2), 305-312.

Lindström, T., Söremark, C., Heinegård, C., and Martin-Löf, S. (1974). "The importance of electrokinetic properties of wood fiber for papermaking," Tappi 57(12), 94-96. 
Lloyd, J. A., and Horne, C. W. (1993). "The determination of fiber charge and acidic groups of radiata pine pulps," Nordic Pulp Paper Res. J. 8(1), 48-67.

Marlow, B. J., Fairhurst, D., and Pendse, H. P. (1988). "Colloid vibration potential and the electrokinetic characterization of concentrated colloids," Langmuir 4(3), 611-626.

Marton, J. (1980). "Role of surface chemistry in fines-alum interactions," Tappi J. 63(2), 121-125.

Marton, J., and Marton, T. (1976). "Wet end starch: Adsorption of starch on cellulosic fibers," Tappi 59(12), 121-124.

Mathews, J., Gustafson, R. and Hodgson, K. (2004). "A method to determine the charge demand of single pulp fibers," Nordic Pulp Paper Res. J. 19(4), 453-459.

McKague, J. F., Etter, D. O., Pilgrim, J. O., and Griggs, W. H. (1974). "Practical applications of the electrokinetics of papermaking," Tappi 57(12), 101-103.

Melzer, J. (1972). "Zeta potential and its importance in the manufacture of paper," Papier 26(7), 305-332.

Miller, N. P., Berg, J. C., and O'Brien, R. W. (1992). "The electrophoretic mobility of a porous aggregate," J. Colloid Interface Sci. 153(1), 237-243.

Miyanishi, T. (1995). "On-line zeta potential analyses of a fine paper machine and a newsprint paper machine," Tappi J. 78(3), 85-91.

Miyanishi, T. (1995). "Effects of zeta potential on flocculation measurement in microparticle systems," Tappi J. 78(11), 135-150.

Miyanishi, T. (1999). "Wet end optimization for a neutral PCC filled newsprint machine," Tappi J. 82(1), 220-225.

Miyanishi, T., and Montegi, S. (1996). "Optimization of flocculation and drainage for microparticle systems by zeta potential control," Proc. 1996 Papermakers Conf., TAPPI Press, Atlanta, 73-82.

Miyanishi, T., and Shigeru, M. (1997). "Optimizing flocculation and drainage for microparticle systems by controlling zeta potential," Tappi J. 80(1), 262-270.

Mocchiutti, P. and Zanuttini, M. A. (2005). "A useful equation for estimating the surface charge of pulp fibers," Tappi J. 4(5), 18-22.

Müller, R. H. (1996). Zetapotential und Partikelladung in der Laborpraxis, Wissenschaftliche Verlagsgesellschaft mbH, Stuttgart, see pp. 104-108.

Nazir, B. A. (1994). "An on-line streaming potential meter (SPM) - Wet-end applications," Paper Technol. Ind. 35(3), 28-35.

Neale, S. M. (1946). "The electrical double layer, the electrokinetic potential, and the streaming current," Trans. Faraday Soc. 42, 473-487.

O'Brien, R. W., and White, L. R. (1978). "Electrophoretic mobility of a spherical colloidal particle," J. Chem. Soc. Faraday Trans II 74(9), 1607-1626.

Öhman, L.-O., Wågberg, L., Malmgren, K., and Tjernström, A. (1997). "Adsorption of aluminum (III) on cellulosic fibers in neutral to alkaline solutions - Influence of charge and size of the particles formed," J. Pulp Paper Sci. 23(10), J467-J474.

Ohshima, H. (1997). "Electrophoretic mobility of a polyelectrolyte-adsorbed particle: Effect of segment density distribution," J. Colloid Interface Sci. 185(1), 269-273.

Ojala, T. (1993). "Charge measurements of different furnishes using polyelectrolyte titration with a streaming current detector," TAPPI Papermakers Conf., 613-626. 
Özdil, N., Özdoğan, E., and Öktoem, T. (2003). "Effects of enzymatic treatment on various spun yarn fabrics," Fibres Textiles in Eastern Europe 11(4), 58-61.

Padovani, E., and Colasurdo, A. R. (1995). "Online real-time measurement reduces wetend variability," Pulp Paper 69(4), 57-62.

Pang, L., and Gray, D. G. "Heterogeneous fibrillation of kraft pulp fiber surfaces observed by atomic force microscopy," J. Pulp Paper Sci. 24(11), 369-372 (1998).

Pelton, R. (1993). "A model of the external surface of wood pulp fibers," Nordic Pulp Paper Res. J. 8(1), 113-119.

Pelton, R., Miller, P., McPhee, W., and Rajaram, S. (1993). "Strategies for improving electrophoresis data from the Coulter DELSA," Colloids Surf. A. 80(2/3), 181-189.

Penniman, J. G. (1991). "A method and apparatus for measuring an electrical characteristic of a fibrous dispersion," Eur. Pat. Appl. 91304556.3.

Penniman, J. G. (1992). "Comparison of pulp pad streaming potential measurement and mobility measurement," Tappi J. 75(8), 111-115.

Penniman, J. G. (1994). "On-line monitoring of micro-particulate papermaking process chemistry," Proc. TAPPI 1994 Papermakers Conf., 229-236.

Petzold, J. C., and Allen, R. A. (1996). "Streaming potential measuring cell," U.S. Patent 5,495,751.

Phipps, J. S. (1999). "Some mechanistic insights for using the streaming current detector to measure wet-end charge," Tappi J. 82(8), 157-165.

Poppel, E. (1992). "The meaning of zeta potential in the wet end of paper manufacture and the possibilities for optimization by means of electrokinetic control," Wochenbl. Papierfabr. 120(14), 565-571.

Pursiheimo, P., and Thomas, S. (1998). "Controlling wet end chemistry based on the WIC system," Proc. Measurement and Control of Papermaking, Pira International, Leatherhead, Surrey, UK, Paper 15.

Quincke, G. (1859). "Concerning a new type of electrical current," Annalen der Physic und Chemie (Poggendorff's Annal., Ser. 2) 107, 1-47.

Räsänen, E., and Stenius, P. (1997). "The sorption of $\mathrm{Na}^{+}, \mathrm{Ca}^{++}, \mathrm{Mg}^{++}$, and $\mathrm{Mn}^{++}$on cellulose fibers: Prediction and analysis of sorption equilibrium with electrostatic models," Proc. ISWPC, Paper 94, 1-5.

Räsänen, E., Stenius, P., and Tervola, P. (2001). "Model describing Donnan equilibrium, $\mathrm{pH}$ and complexation equilibria in fiber suspensions," Nordic Pulp Paper Res. J. 16(2), 130-139.

Revil, A., Pezard, P. A., and Glover, P. W. J. (1999). "Streaming Potential in Porous Media. 1. Theory of the Zeta Potential," J. Geophys. Res. 104(B9), 20021-20031.

Richter, R., Rohloff, E., Tretter, H., Müller, F., and Penniman, J. G. (1989). "A new instrument for automatic streaming potential measurements on the paper machine," Wochbl. Papierfabr. 117(15), 682-686.

Ricq, L., Pierre, A., Reggiani, J.-C., Pagetti, J., and Foissy, A. (1998). "Use of electrophoretic mobility and streaming potential measurements to characterize electrokinetic properties of ultrafiltration and microfiltration membranes," Colloids Surf. A 138(2-3), 301-308.

Roberts, J. C., and Tatham, J. (1992). "Succinylation of pulps," in The Chemistry of Papermaking, paper 08, Pira Int'1., Leatherhead, Surrey, UK. 
Rojas, O. J., Claesson, P. M., Muller, D., and Neuman, R. D. (1998). "The effect of salt concentration on adsorption of low-charge-density polyelectrolytes and interactions between polyelectrolyte-coated surfaces," J. Colloid Interface Sci. 205(1), 77-88.

Rojas, O. J., Ernstsson, M., Neuman, R. D., and Claesson, P. M. (2000). "X-ray photoelectron spectroscopy in the study of polyelectrolyte adsorption on mica and cellulose," J. Phys. Chem. B 104(43), 10032-10042.

Rojas, O. J., and Neuman, R. D. (1999). "Adsorption of polysaccharide wet-end additives in papermaking systems," Colloids Surf. A 155(2-3), 419-432.

Rohloff, E., and Höschle, O. (1993). "Zeta potential experiences with laboratory and online measurements," Wochenbl. Papierfabr. 121(23-24), 990-994.

Rundlöf, M., Htun, M., Höglund, H., and Wågberg, L. (2000). "Mechanical pulp fines of poor quality - Characteristics and influence of white water," J. Pulp Paper Sci. 26(9), 308-316.

Sack, W. (1976). "Continuous measurement of streaming potential on a paper machine," Papier 30(10A), V42-V46.

Sack, W., Storbeck, W., and Winiker, R. (1993). "Ten years of research experience with continuous zeta potential measurements for paper machine process control," Wochbl. Papierfabr. 121(19), 803-805.

Saito, T., and Isogai, A. (2005). "A novel method to improve wet strength of paper," Tappi J. 4(3), 3-8.

Sanders, N. D. (1994). "The occurrence and importance of polymodal electrophoretic mobility distributions," in B. M. Moudgil and P. Somasundaran, eds., Dispersion Aggregation, Proc. Eng. Found. Conf. 1992, 183-190.

Scales, P. J., Grieser, F., Healy, T. W., White, L. R., and Chan, D. Y. C. (1992). "Electrokinetics of the silica-solution interface: A flat plate streaming potential study," Langmuir 8(3), 965-974.

Scallan, A. M. (1983). "The effect of acidic groups on the swelling of pulps: A review," Tappi J. 66(11), 73-75.

Scallan, A. M. (1989). "The electrical conductance of pulp suspensions," Tappi J. 72(11), 157-162.

Schurz, J., Ribitsch, V., and Jacobasch, H.-J. (1989). "Zeta potential as a means of characterizing surfaces," Wochenbl. Papierfabr. 117(11/12), 525-529.

Schwarz, S., Buschhammer, H.-M., Lunkwitz, K., and Jacobasch, H.-J. (1998). "Polyelectrolyte adsorption on charged surfaces: Study by electrokinetic measurements," Colloids Surf. A 140(1-3), 377-384.

Sennett, P., and Olivier, J. P. (1965). "Colloidal dispersion, electrokinetic effects and the concept of zeta potential," Indus. Eng. Chem. 57(8), 33-50.

Sezaki, T., Hubbe, M. A., Heitmann, J. A., Argyropoulos, D. S. (2006). "Colloidal effects of acrylamide polyampholytes. Part 2. Adsorption onto cellulosic fibers," Colloids and Surfaces A, in print.

Smith, D. C. (1992). "Chemical additives for improved compression strength of unbleached board," Proc. TAPPI 1992 Papermakers Conf., TAPPI Press, Atlanta, 393-404. 
Spence, G. G., Underwood, R. T., and Yarnell, J. R. (1997). "A titration procedure for determining the level of anionic impurities in a pulp furnish," PaperAge 113(7), 3031.

Springer, A. M., and Taggart, T. E. (1986). "Quantitative evaluation of alternative methods of determining total charge," Tappi J. 69(5), 116-121.

St. John, M. R., and Gallagher, T. M. (1992). "Evaluation of the charge state of papermachine systems using the charge titration method," Proc. 1992 TAPPI Papermakers Conf., TAPPI Press, Atlanta, 479-502.

Stark, H., and Eichinger, R. (1989). "Effect of zeta potential on the adsorption tendency and degree of organization of fiber suspensions," Wochenbl. Papeirfabr. 117(11/12), 521-524.

Stitt, J. B. (1998). "Charge control helps tissue producers achieve quality, productivity benefits," Pulp Paper 72(5), 109-114.

Stone, J. E., and Scallan, A. M. (1966). "Influence of drying on the pore structures of the cell wall," in R, Bolam, ed., Consolidation of the Paper Web, Vol. 1, British Paper \& Board Makers Assoc., 145-174.

Stone, J. E., and Scallan, A. M. (1968). "A structural model of the cell wall of waterswollen wood pulp fibers based on their accessibility to macromolecules," Cellulose Chem. Technol. 2(3), 343-358.

Stratton, R. A., and Swanson, J. W. (1981). "Electrokinetics in papermaking. A position paper," Tappi 64(1), 79-83.

Strazdins, E. (1972). "Factors affecting the electrokinetic properties of cellulose fibers," Tappi 22(12), 1691-1695.

Strazdins, E. (1977). "Optimization of the papermaking process by electrophoresis," Tappi 60(7), 113-114.

Strazdins, E. (1980). "New approaches towards optimizing dry strength of waste paper containing stock furnishes," Papier 34(10A), V49-V55.

Strazdins, E. (1994). "Application of electrokinetics in optimization of wet-end chemistry," in L. L. Chan, ed., Wet-Strength Resins and their Application, TAPPI Press, Atlanta, 63-83.

Strazdins, E. (1995). "Critical issues in applying electrokinetics to papermaking," Tappi J. 78(8), 115-119.

Sukhorukov, G. B., Donath, E., Lichtenfeld, H., Knippel, E., Knippel, M., Budde, A., and Möhwald, H. (1998). "Layer-by-layer self assembly of polyelectrolytes on colloidal particles," Colloids Surf. A 137(1-3), 253-266.

Tanaka, H. (1984). "Studies on wet-end chemistry in papermaking. 2. Some considerations on physicochemical properties of mill white waters," Japan Tappi 38(8), 844-850.

Tanaka, H. (1984). "Studies on wet-end chemistry in papermaking. 3. Problems in measurement of zeta potential and characteristics of zeta potential of suspended solids in mill white waters," Japan Tappi 38(9), 965-972.

Tanaka, H., Ueda, I., Ichiura, H., and Kitaoka, T. (2000). "Determining cationic demand of suspensions using chromo-PDADMAC," Proc. Intl. Symp. Environ. Friendly Emerging Technol. Sustainable Pulp Paper Ind., TFRI Extension Ser. 115, 68-71. 
Tatsumi, D., and Yamauchi, T. (1997). "Depth profile of paper additives within a pulp fiber," in C. F. Baker, ed., The Fundamentals of Papermaking Materials, Pira Intl., Leatherhead, UK, 789-814.

Terayama, H. (1952). "Method of colloid titration (A new titration between polymer ions)," J. Polym. Sci. 8(2), 243-253.

Thiele, B., and Kopp, J. W. (1997). "Charge balances of paper machine systems - A method of process optimization," Wochenbl. Papierfabr. 125(11/12), 542-556.

Tripattharanan, T., Hubbe, M. A., Heitmann, J. A., and Venditti, R. A. (2004). "Effect of idealized flow conditions on retention and performance. Part 2. Polymer bridging, charged patches, and charge neutralization," Appita J. 57(6), 448-454.

van de Steeg, T. G. M., Cohen Stuart, M. A., de Keizer, A., and Bijsterbosch, B. H. (1992). "Polyelectrolyte adsorption: A subtle balance of forces," Langmuir 8, 25382546.

van de Ven, T. G. M. (1999). "Effect of fiber conductivity on zeta potential measurements of pulp fibers," J. Pulp Paper Sci. 25(7), 243-245.

Vanderhoek, N. (1994). "Optimizing paper machine performance through electrokinetic measurement," Appita J. 47(5), 397-401.

Van Wagenen, R. A., and Andrade, J. D. (1980). "Flat-plate streaming potential investigations - Hydrodynamics and electrokinetic equivalency," J. Colloid Interface Sci. 76(2), 305-314.

Varoqui, R. (1982). "Effect of polymer adsorption on the electrophoretic mobility of colloids," Nouv. J. Chimie 6(4), 187-189.

Veal, C. R. (1997). "On-line cationic demand measurement for wet end papermaking," Proc. TAPPI 1997 Engineering Papermakers Conf., TAPPI Press, Atlanta, 287-296.

Vernhet, A., Bellon-Fontaine, M. N., and Doren, A. (1994). "Comparison of three electrokinetic methods to determine the zeta potential of solid surfaces," J. Chim. Phys. 91(11/12), 1728-1747.

Verwey, E. J. W., and Overbeek, J. Th. G. (1948). Theory of the Stability of Lyophobic Colloids, Elsevier, New York.

Wågberg, L., and Björklund, M. "On the mechanism behind wet strength development in papers containing wet strength resins," Nordic Pulp Paper Res. J. 8(1), 53-58.

Wågberg, L., and Ödberg, L. (2000). "Polymer adsorption onto cellulose fibers - A review," Nordic Pulp Paper Res. J. 15(5), 586-597.

Wågberg, L., Ödberg, L., and Glad-Nordmark, G. (1989). "Charge determination of porous substrates by polyelectrolyte adsorption," Nordic Pulp Paper Res. J. 4(2), 7176.

Walecka, J. A. (1956). "An investigation of low degree of substitution carboxymethylcelluloses," Tappi 39(7), 458-463.

Walker, C. A., Kirby, J. T. and Dentel, S. K. (1996). "The streaming current detector: A quantitative model," J. Colloid Interface Sci. 182(1), 71-81.

Wan, Q.-H. (1997). "Effect of electrical double-layer overlap on the electroosmotic flow in packed-capillary columns," Anal. Chem. 69(3), 361-363.

Wang, F., and Hubbe, M. A. (2001). "Development and evaluation of an automated streaming potential measurement device," Colloids and Surfaces A 194(1-3), 221232. 
Wang, F., and Hubbe, M. A. (2002). "Charge properties of fibers in the paper mill environment. 1. Effect of electrical conductivity," J. Pulp Paper Science 28(10), 347353.

Winters, J. C. (1998). "Introduction to the electrokinetics of papermaking," in J. M. Gess, ed., Retention of Fines and Fillers during Papermaking, TAPPI Press, Atlanta, Ch. 3, 29-50.

Article submitted: May 8, 2006; Revision accepted: July 1, 2006; Published: July 26, 2006 